\title{
Bond Formation Mechanism for Resistance Welding of X70 Pipeline Steel
}

\author{
A Gleeble ${ }^{\circledR}$ thermo-mechanical simulator was used to \\ physically simulate the seam weld formation during resistance welding
}

\author{
BY R. KANNAN, L. LI, L. GUO, N. ANDERSON, M. RASHID, L. COLLINS, AND M. ARAFIN
}

\begin{abstract}
A Gleeble ${ }^{\circledR}$ thermo-mechanical simulator combined with microstructure characterization using a field emission scanning electron microscope was used to provide insights into the seam weld formation during resistance welding (RW). Gleeble ${ }^{\circledR}$ was used to physically/microstructurally simulate the seam weld formation during RW for the first time. It was found that a peak temperature of $1500^{\circ} \mathrm{C}$ and $10-\mathrm{mm}$ stroke produced a microstructure in the solid-state bondline, the flash, and the heat-affected zone similar to the resistance welded pipe manufactured in an industrial scale. Using the force response obtained during seam weld formation in Gleeble ${ }^{\circledR}$, microstructure characterization of the seam weld, and thermodynamic calculations, it is proposed the seam weld in a resistance weld consists of a mushy zone with delta ferrite and solute-enriched liquid, which solidifies into austenite, and on post welding cooling, transforms into ferrite and stringers of $M / A$, respectively. The presence of a mushy zone in the weld joints provides a physical explanation for the "decarburization" phenomenon observed in the seam of resistance welds.
\end{abstract}

\section{KEYWORDS}

- Gleeble ${ }^{\circledR}$ - Resistance Welding • Physical Simulation

- Joint Formation • Decarburization • Mushy Zone

\section{Introduction}

Line pipes continue to be the most preferred, cost-effective, and safest mode of transporting oil and natural gas. The American Petroleum Institute and Canadian Standards Association specifications are generally used for manufacturing and testing the quality of line pipes produced in North America. Welding is one of the main manufacturing processes for line pipes production in a large scale. Manufacturing of welded pipe involves cold forming of the skelp (cast steel that is thermo-mechanically controlled processed $[\mathrm{TMCP}])$ to the desired pipe diameter, followed by seam welding of the edges.

Submerged arc welding (Ref. 1) and resistance welding (RW) (Refs. 2-22) are the two most commonly practiced welding methods for large-scale production of line pipe. In RW, the hot-rolled skelp is progressively cold formed into a tubular shape to the desired pipe diameter by means of progressive forming rolls. High-frequency resistance welding (HF-RW) is an automated, relatively high-speed, autogenous welding process that does not require any special filler metal or consumable. HF-RW operates on the principle of Joule heating, where electrical current passes through the material, and because of the material's inherent resistance to current, heat is generated depending on the magnitude of current used. A variation of HF-RW uses induced current (high-frequency induction welding) to heat the faying surfaces of the skelp. Considering the high frequency of the current used in the welding process, by skin effect and the proximity effect, the Joule heat generated during the process is confined to a very small region in relation to the pipe, resulting in a narrow heat-affected zone (HAZ) in comparison to the pipe wall thickness as well as an hourglass-shaped HAZ (Ref. 14).

Finally, once the skelp edges are heated to the desired peak temperature (close to melting point of the steel), then a high degree of deformation (called the weld squeeze) is applied. The weld squeeze causes the molten material and any high-temperature iron oxides formed at the joint interface to be extruded to the inner diameter (ID) and outer diameter (OD) surfaces of the pipe in the form of flash (Ref. 13). This extruded flash is removed from both the ID and OD surfaces following welding, before further processing. One of the interesting observations reported by many researchers, and commonly accepted, is that the weld joint itself is considered to be lower in carbon or "decarburized" 


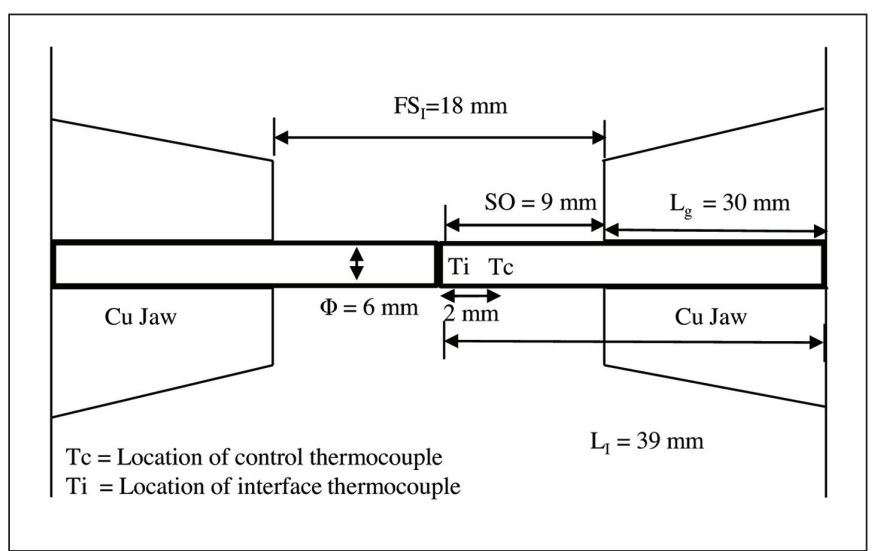

Fig. 1 - Setup of the Gleeble ${ }^{\circledR}$ simulation experiments for both round bar and plane strain rectangular bar samples.

(Refs. 22-26). Changchun (Ref. 24) reported the carbon concentration in the weld joint can be $30 \%$ lower than that of the base metal, and the decarburized zone represents a zone of weakness. However, the weld joint is considered to be decarburized, based on the etching response of the bondline in comparison to the surrounding base metal (Ref. 24); to the authors' knowledge, neither a scientific explanation for the decarburzation process nor an experimental verification of the decarburization at the bondline has been reported. Experimental quantification of decarburization is necessary to understand the subsequent phase transformations/ microstructure evolution during cooling/postweld normalizing heat treatments, and, in turn, understand the effect of microstructure on the mechanical properties of the joint.

With the assumption that the bondline is decarburized, to homogenize the carbon concentration across the weld joint and to reduce the postweld residual stresses, the pipe undergoes a postweld normalizing treatment, where the seam weld is heated to above the austenitization temperature to match the seam weld properties with that of the base metal. The low temperature toughness of the pipe following normalizing is one of the most critical mechanical properties for integrity assurance during operation of line pipes. Achieving superior low temperature toughness in RW line pipes has been a challenging problem owing to the lack of availability of literature, a poor understanding of the process, and the difficulty of simulating the welding process.

Several studies have been carried out to understand critical factors associated with poor low temperature toughness of RW line pipe, including welding speed (Refs. 4, 7, 12), microstructure after postweld normalizing treatment (Refs. 2, 22), texture (Refs. 3, 22), and the effect of postweld normalizing temperature, as well as center line segregation of the base metal (Ref. 10). Research has also shown within $\pm 0.5 \mathrm{~mm}$ of the seam weld is usually where the lowest toughness is observed (Ref. 17). In the majority of the previous research related to RW, Gleeble ${ }^{\circledR}$ thermo-mechanical simulator and numerical modeling (Refs. 19, 20) have been widely used to understand the microstructure evolution and the physics of the process during RW. Gleeble ${ }^{\circledR}$-based postweld normalizing schedules have been developed to improve the low temperature toughness performance of the seam weld (Refs. 2, 22). In most of these studies, postweld normalizing was conducted either on the base metal (Ref. 22) or on the as-welded samples (Ref. 2). Conducting postweld normalizing on the base metal will not be accurate since the prior as-welded deformation history is not present. Introducing deformation in the base metal at a laboratory scale prior to postweld normalizing experiments is challenging due to the difficulty in estimating the accurate strain rate

Table 1 - Nominal Chemical Composition of the Base Material Used in This Study (compositions are in wt-\%)

\begin{tabular}{cccccrr}
$C$ & $\mathrm{Nb}$ & $\mathrm{Ti}+\mathrm{V}$ & $\mathrm{Mn}$ & $\mathrm{Si}$ & $\mathrm{Cu}+\mathrm{Ni}+\mathrm{Cr}+\mathrm{Mo}$ & $\mathrm{N}$ \\
\hline 0.043 & 0.068 & 0.025 & 1.65 & 0.18 & 0.672 \\
\hline
\end{tabular}

Table 2 - Experimental Conditions Used for Physical Simulation Experiments

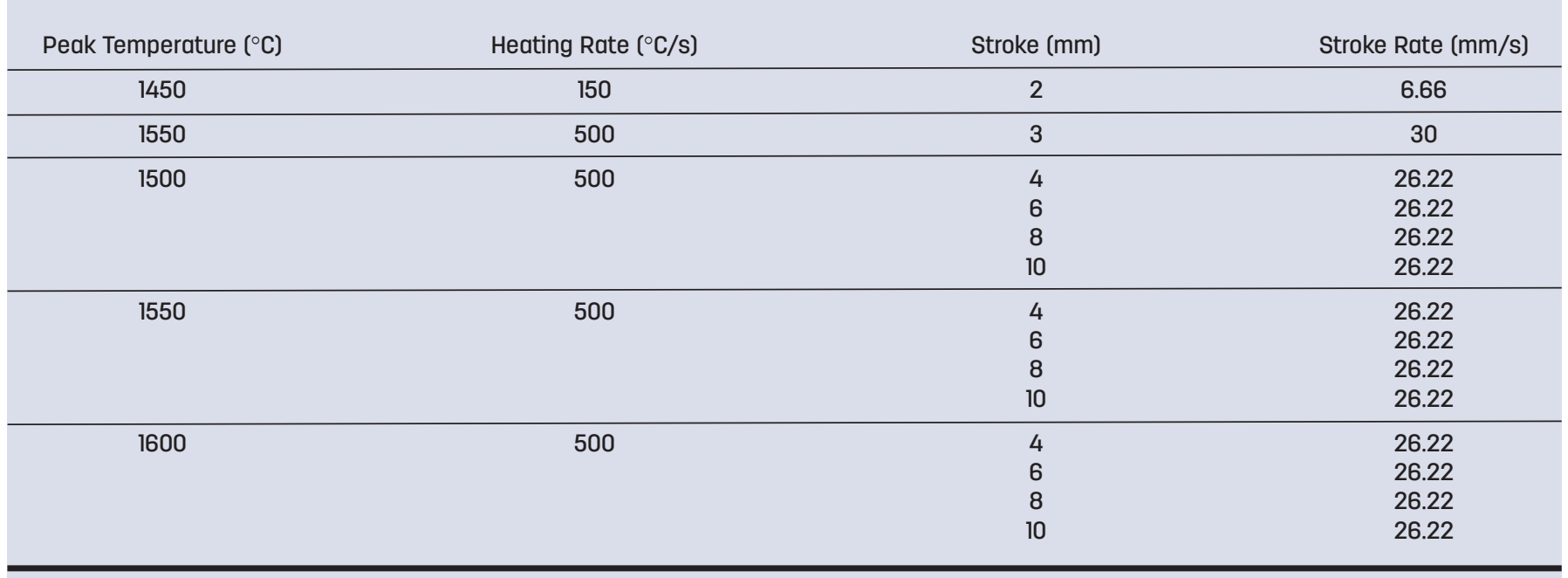



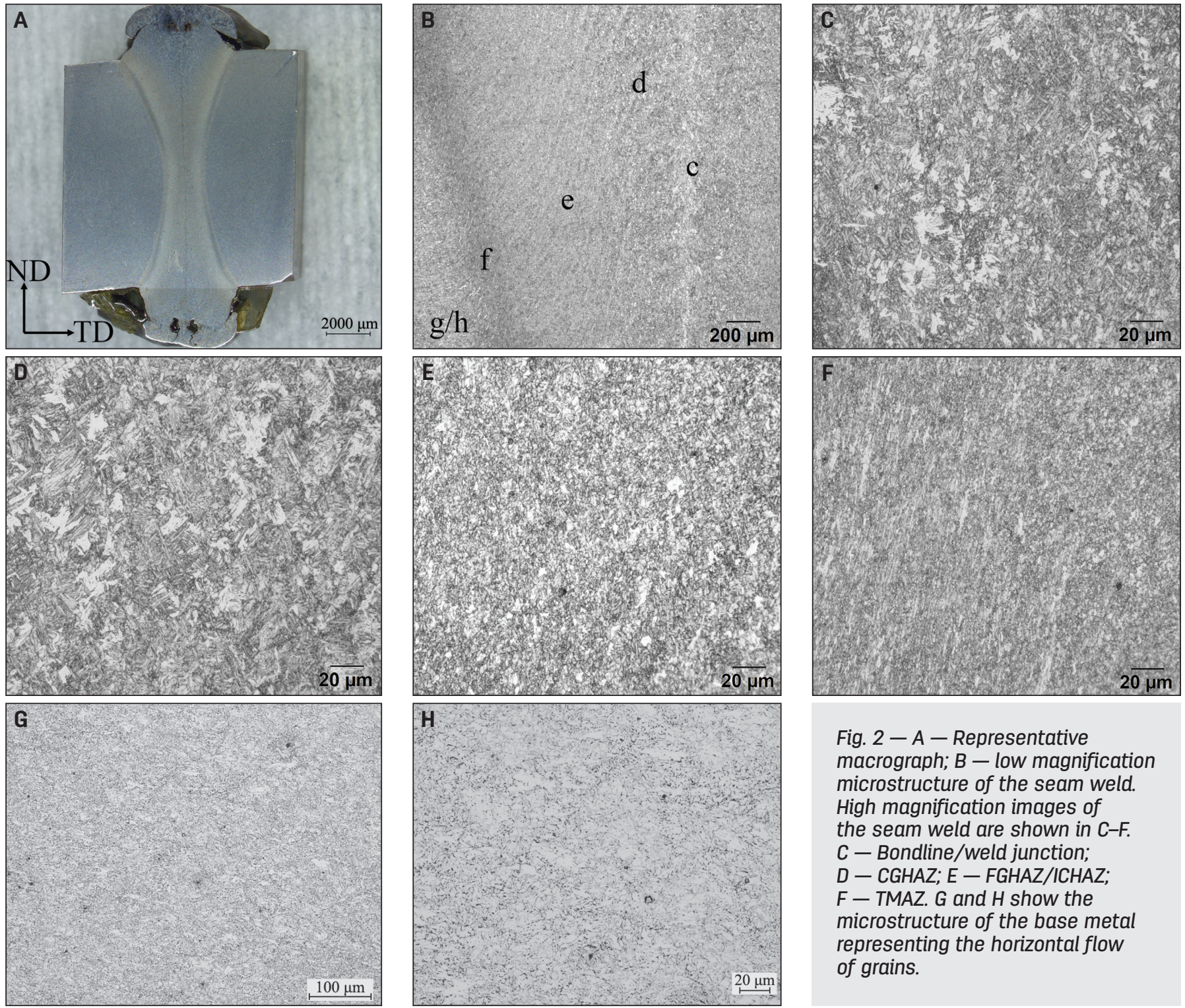

Fig. $2-A-$ Representative macrograph; B - low magnification microstructure of the seam weld. High magnification images of the seam weld are shown in $C-F$. $C-$ Bondline/weld junction: D - CGHAZ; E - FGHAZ/ICHAZ; $F-T M A Z$. $G$ and $H$ show the microstructure of the base metal representing the horizontal flow of grains.

and strain level, which will be representative of the bondline. While conducting postweld normalizing trials on the as-welded samples overcomes this difficulty, it comes with associated downtime costs, since the production line has to be stopped temporarily to extract as-welded samples for postweld normalizing trials in Gleeble ${ }^{\circledR}$.

To overcome the above-mentioned difficulties, the main purposes of this article are to physically simulate the RW seam weld formation in Gleeble ${ }^{\circledR}$, and using the Gleeble ${ }^{\circledR}$ recorded process variables, propose a mechanism for the joint formation and decarburization phenomenon at the weld joint during RW. Previously, quantitatively characterizing the RW has been difficult due to the continuous/highspeed nature of the welding process. On the other hand, the Gleeble ${ }^{\circledast}$ apart from the low-frequency resistive heating, if it can reproduce the RW bonding, will measure all the process parameters. This will provide a quantitative description of the RW bond formation process. Thus, a successful physical simulation using Gleeble ${ }^{\circledR}$ will help understand the effect of process parameters (weld squeeze, peak temperature) on the seam weld formation at a laboratory scale before conducting mill-scale trials.

\section{Experimental Procedure}

The material used in this study is an X70 pipeline steel with a nominal composition, as shown in Table 1 . The base material steel was produced by TMCP (refer to Fig. $2 \mathrm{G}$ and $\mathrm{H}$ for original base metal microstructure).

Physical simulation experiments were conducted on a Dynamic Systems Inc. Gleeble ${ }^{\circledR} 800$ thermo-mechanical simulator. Three different simulation experiments were conducted in Gleeble ${ }^{\circledR}$. First, the critical condition for formation of a resistance weld with flash in Gleeble ${ }^{\circledR}$ was identified. For this, two tests with different peak temperatures $\left(1450^{\circ}\right.$ and $\left.1550^{\circ} \mathrm{C}\right)$ were performed. Using the inputs from the initial tests, a systematic study of varying the peak temperature (from $1500^{\circ}$ to $1600^{\circ} \mathrm{C}$ ) and stroke (from 4 to $10 \mathrm{~mm}$ ) at a constant heating rate of $500^{\circ} \mathrm{C} / \mathrm{s}$ and stroke rate of $26.22 \mathrm{~mm} / \mathrm{s}$, which are representative of the industrial RW conditions, was carried out on 


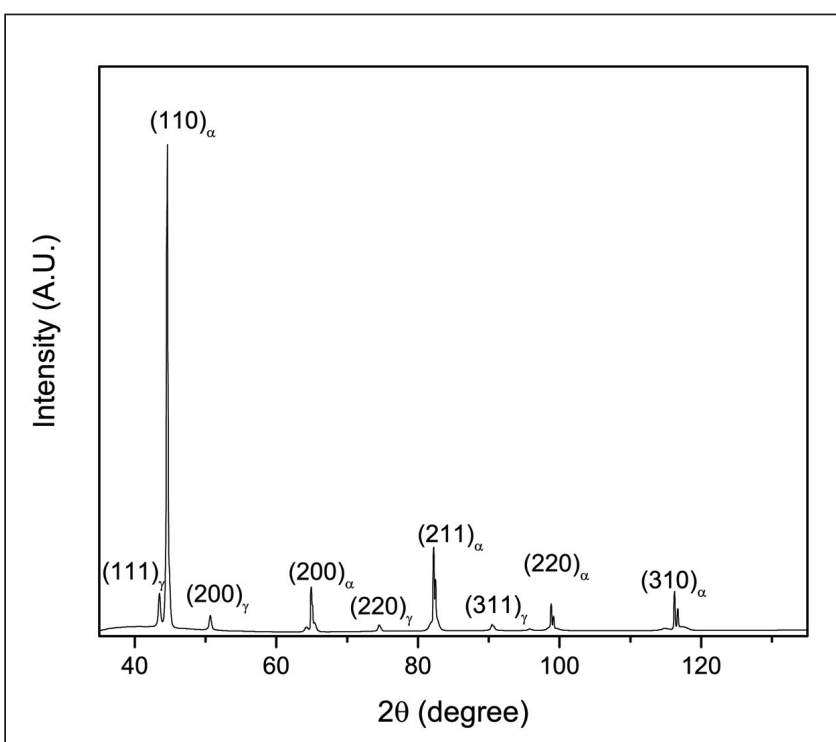

Fig. 3 - Representative $x$-ray diffraction profile from the seam weld (weld junction + HAZ + TMAZ).

cylindrical samples with $39 \mathrm{~mm}$ length and a diameter of 6 $\mathrm{mm}$. Finally, to simulate the plane strain conditions during the industrial welding, physical simulations at a peak temperature and heating rate of $1500^{\circ} \mathrm{C}$ and $500^{\circ} \mathrm{C} / \mathrm{s}$ with a stroke and stroke rate of $10 \mathrm{~mm}$ and $26.22 \mathrm{~mm} / \mathrm{s}$, respectively, were carried out on rectangular samples with $10 \mathrm{~mm}$ width, $5 \mathrm{~mm}$ thickness, and $39 \mathrm{~mm}$ length. The experimental conditions for the Gleeble ${ }^{\circledR}$ experiments are shown in Table 2.

One of the critical issues that needs to be taken into account during the physical simulation experiments is the control thermocouple spot welded to the interface of the samples must not lose contact during the application of the stroke. For this purpose, two sets of thermocouples were spot welded to the specimens; the first one at the bonding interface, and the other $2 \mathrm{~mm}$ away from the interface. The thermocouple set located $2 \mathrm{~mm}$ away from the interface was used as the control thermocouple, and the interface thermocouple recorded the interfacial temperature until the application of stroke - Fig. 1.

Following the physical simulation experiments in Gleeble ${ }^{\circledR}$, both the Gleeble ${ }^{\circledR}$ welded samples and the industrially resistance welded pipe samples were cut along the normal-transverse direction (ND-TD) plane, and the ND-TD plane was ground and polished using standard metallography procedures. For microstructure comparison, in the ND-TD plane, the samples were etched with $2 \%$ nital. To reveal the microstructure at a finer scale, a Zeiss Sigma field emission scanning electron microscope (FESEM) combined with XMax energy-dispersive x-ray (EDX) spectroscopy was used. Micro Vickers hardness mapping was conducted using a Wilson VH3100 hardness tester with Minuteman software. First, a coarser hardness map with $\mathrm{x}$ spacing of $80 \mu \mathrm{m}$ and a y spacing of $450 \mu \mathrm{m}$ was conducted from the OD of the pipe to the ID of the pipe across the coarse grained heat-affected zone (CGHAZ) and bondline. Second, to reveal the hardness distribution at finer levels, a finer map with $\mathrm{x}$ spacing of $80 \mu \mathrm{m}$ and a y spacing of 80 $\mu \mathrm{m}$ was conducted at the OD, ID, and the mid-wall thick- ness of the pipe across the CGHAZ and bondline. Both the hardness maps were conducted with a load $0.05 \mathrm{kgf}$ and a dwell time of $10 \mathrm{~s}$.

\section{Results}

\section{Industrially Manufactured RW Pipe in the As-Welded Condition}

Figure 2 shows the typical macrograph and the microstructure of the seam weld of an industrially manufactured X70 line pipe in the as-welded condition. It can be seen from the macrograph in Fig. 2A that the definitive features for the RW joint include the thin bondline, the hourglass-shaped HAZ, and the flash. Figure 2B shows the low magnification microstructure of the seam weld of the industrially produced pipe. It can be seen that four distinct zones (labeled as c to f) are distinguishable. At higher magnification, the bondline (zone c) appears lighter, and is the weld junction between the two edges of the skelp that has undergone severe deformation and experienced the maximum temperature during the welding process. Away from zone c, there is the HAZ (zone d), which experienced a relatively lower temperature and deformation in comparison to zone c. Away from zone d, into zone e and zone f, plastic flow of grains can be observed. Figure $2 \mathrm{C}$ shows the high magnification image of the bondline. It can be seen that the microstructure consists of acicular/needle-like features, which are most likely bainitic ferrite (needle-like structure features in the microstructure formed at a temperature of about $500^{\circ} \mathrm{C}$ ) and some polygonal ferrite (equiaxed ferrite structure features at higher temperature near the Ar1 temperature). In the HAZ in Fig. 2D, the microstructure is similar to the bondline with the presence of bainitic ferrite and polygonal ferrite. Zone $d$ has a microstructure similar to the CGHAZ of a fusion weld. Away from the HAZ (Fig. 2D), in Fig. $2 \mathrm{E}$, the microstructure is predominantly polygonal ferrite with minor fractions of bainitic ferrite.

It is likely that zone e is either the fine grained heataffected zone (FGHAZ) or the intercritical heat-affected zone (ICHAZ); the small area makes distinguishing the two difficult. High magnification microstructure of zone $\mathrm{f}$ in Fig. $2 \mathrm{~F}$ consists of polygonal ferrite, which have been deformed along the metal flow direction during welding. The structure of zone $\mathrm{f}$ is similar to that of the base metal, except that the shapes of the ferrite grains are anisotropic and aligned along the direction of metal flow during welding due to the applied deformation/ weld squeeze. Some researchers have even reported the observed flow behavior is a consequence of the severe pancaking of the high-temperature austenite before it transforms into ferrite (Refs. 22, 27). Though accurate temperature measurements are needed from zone $\mathrm{f}$ to state with certainity that the microstructure of zone $f$ is entirely due to deformation of base metal ferrite or due to pancaking of austenite before it transforms into ferrite, based on the observed structure features, it can be concluded zone $\mathrm{f}$ is the TMAZ. It should be noted that, unlike the weld junction which shows a vertical flow line, the base metal microstructure in Fig. $2 \mathrm{G}$ and $\mathrm{H}$ shows horizontal flow of grains originating due to the TMCP production of the base metal.

To verify the microstructure of the seam weld is indeed fer- 

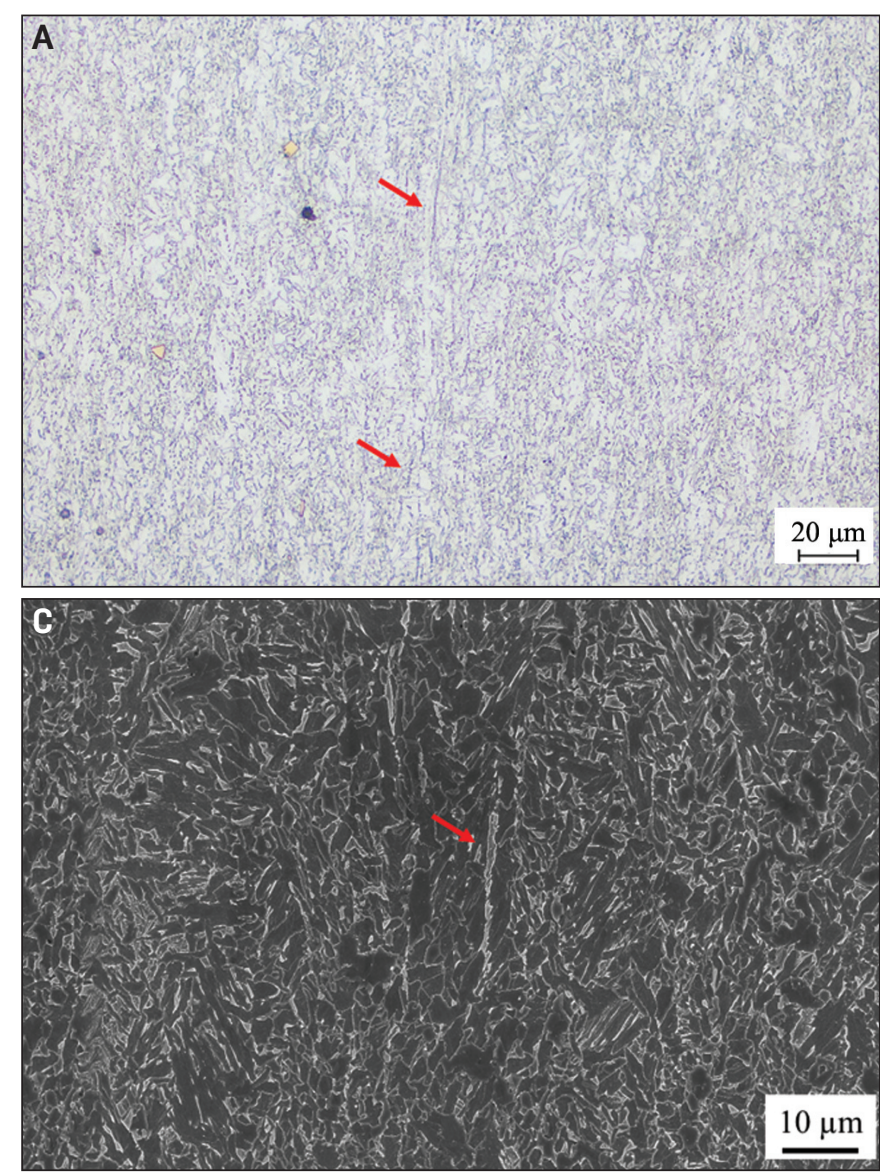

Fig. 4-A - Optical micrograph of the weld junction showing the presence of second phase stringers (marked by red arrows); B - low magnification secondary electron FESEM image of the stringer phase (marked by a red arrow); $C, D-$ high magnification secondary electron FESEM images of the stringer phase; $E$ - elemental EDX line scan profiles corresponding to the white arrow in $D$.

rite (polygonal/bainitic), XRD was performed with the $\mathrm{x}$-ray beam focused on the bondline and the adjacent HAZ regions (approximately a $3-5 \mathrm{~mm}$ wide region). The XRD profile in Fig. 3 shows the predominant diffraction peaks are from ferrite. Thus, the XRD result in Fig. 3 confirms the microstructure in the seam weld is predominantly ferritic (either of the ferrite microstructure, i.e., polygonal ferrite/bainitic ferrite/acicular ferrite).

It should be noted at the seam weld, stringers of second phase (Fig. 4A-D) are present parallel to the welding direction. Such stringers are found across the entire thickness of the weld junction (from OD to ID). Composition analysis using EDX across these stringers in Fig. 4E (corresponding to Fig. 4D) show the stringers are enriched in $C, N$, and other substitutional solutes, and away from the stringer phase, the solutes are depleted. Considering the enrichment in solutes in the stringer phase, it can be suggested the stringer phase are M/A modules. A similar stringer-type second phase was also found in the work by Yan (Ref. 22) in X65 high frequency induction welded (HF-IW) samples, and their focused ion beam/transmission electron microscopy work confirmed the stringer phase was elongated M/A micro constituents.
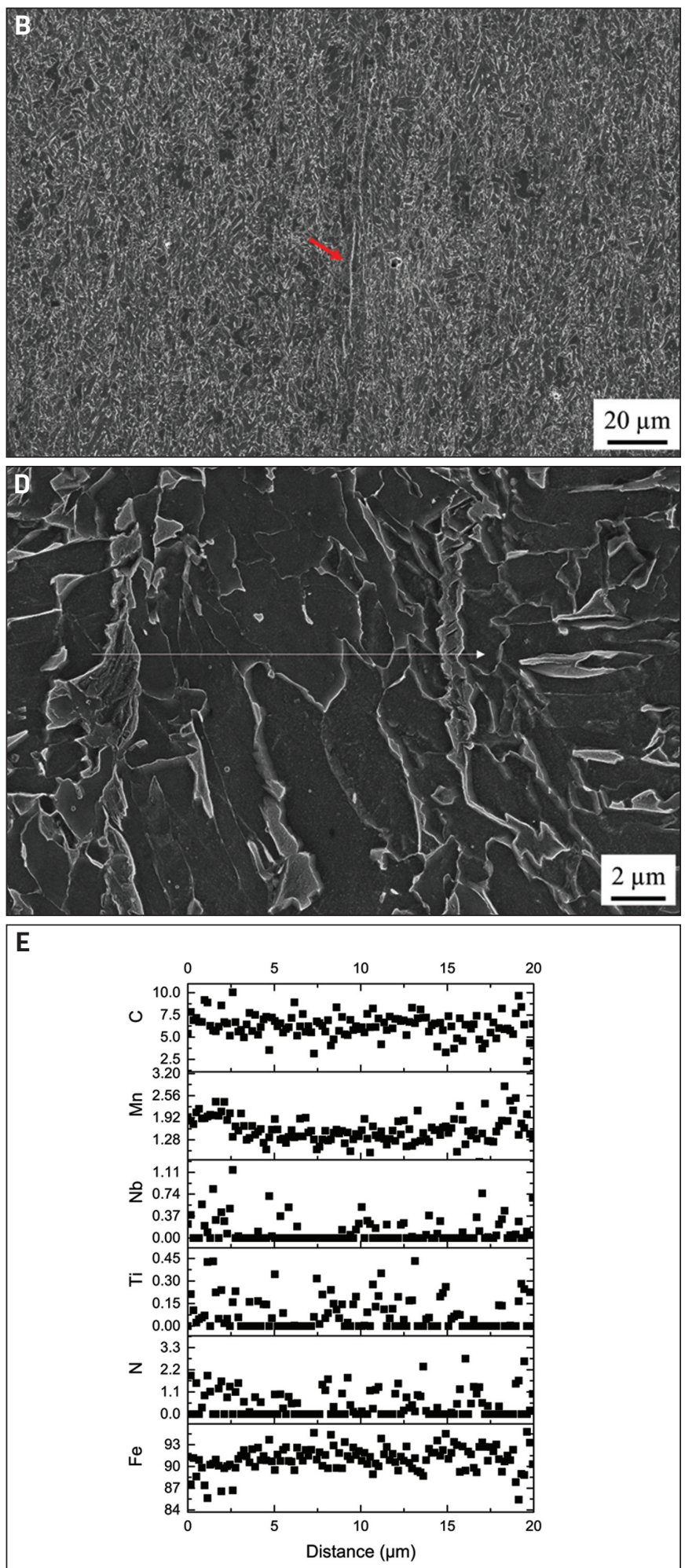

Microhardness mapping across the CGHAZ and the bondline are shown in Fig. 5. From the coarse hardness map shown in Fig. 5A (x spacing of $80 \mu \mathrm{m}$ and y spacing of $450 \mu \mathrm{m}$ ), it can be seen that the average hardness away from the center is around $260 \mathrm{HV}$ 0.05. Near the center (approximate location of the bondline), regions with lower hardness (approximately $230 \mathrm{HV}$ 0.05) are found across the entire length of the bond- 

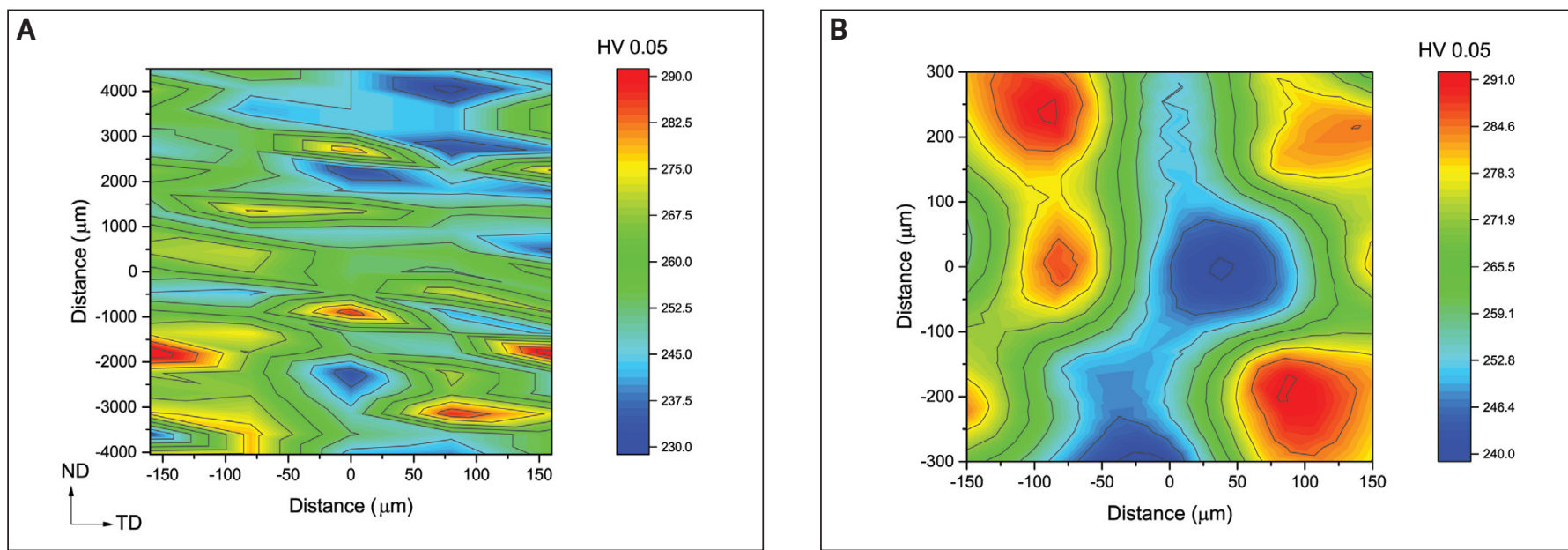

Fig. 5 - Hardness map across the CGHAZ and bondline. A - Coarser hardness map with $x$ spacing of $80 \mu \mathrm{m}$ and $y$ spacing of 450 $\mu \mathrm{m}$ at a load of $0.05 \mathrm{kgf} ; \mathrm{B}$ - finer hardness map with $x$ spacing of $80 \mu \mathrm{m}$ and $y$ spacing of $80 \mu \mathrm{m}$ at a load of $0.05 \mathrm{kgf}$.
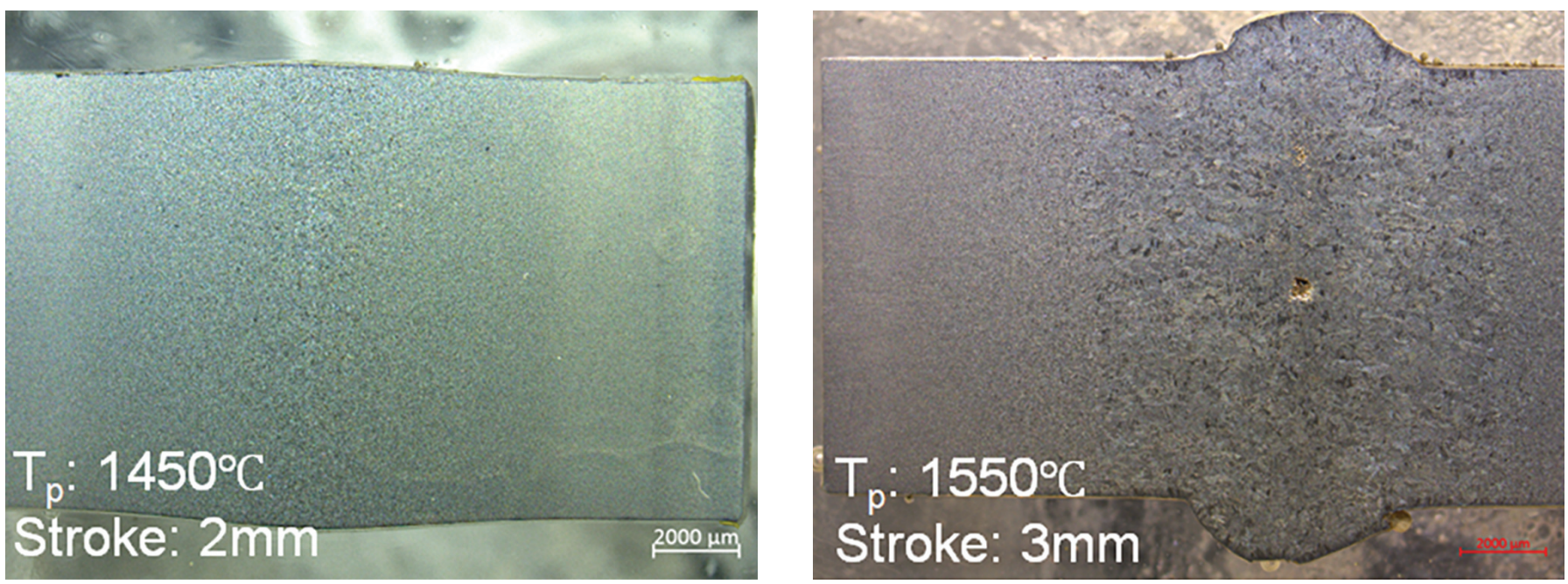

Fig. 6- Optical macrograph of the initial Gleeble ${ }^{\circledR}$ physical simulation samples at a lower peak temperature and lower stroke, and higher peak temperature and higher stroke.

line along the thickness of the pipe (from OD to ID). To visualize the hardness variation at finer scales, a finer hardness map (x spacing of $80 \mu \mathrm{m}$ and y spacing of $80 \mu \mathrm{m}$ ) was conducted, and the result is shown in Fig. 5B. It can be seen from Fig. 5B the bondline is consistently lower in hardness (approximately $240 \mathrm{HV} 0.05$ ) in comparison to the CGHAZ (approximately 290 HV 0.05), confirming the coarser hardness map in Fig. 5A.

Thus, the vertical stringers in the seam weld, and the microstructure within $0.5 \mathrm{~mm}$ of the seam weld (bondline in Fig. 2C and CGHAZ in Fig. 2D) were taken as definitive features for the RW joint. The physical simulation experiments in Gleeble ${ }^{\circledR}$, discussed next, will be judged by the successful reproduction of these features.

\section{Gleeble $^{\circledR}$-Based Physical Simulation Experiments}

\section{Peak Temperature to Form the Flash}

Figure 6 shows the macrographs of the initial Gleeble ${ }^{\circledR}$ simulation experiments with a peak temperature of $1450^{\circ}$ and $1550^{\circ} \mathrm{C}$, and a stroke of 2 and $3 \mathrm{~mm}$, respectively (refer to Table 1). It can be seen when the peak temperature is below the liquidus, a cold weld is formed, but there is no flash. When the peak temperature is above the liquidus temperature, and the stroke is low $(3 \mathrm{~mm})$, a fusion welded joint is formed between the two base metal samples.

Based on the initial results of the Gleeble ${ }^{\circledR}$ physical simulation experiments in Fig. 6, a more systematic study with a temperature higher than the liquidus temperature and higher stroke was carried out (refer to Table 1 ). The results are discussed in the following section.

\section{Stroke to Form the Bondline}

Figure 7 shows the macrographs of all the Gleeble ${ }^{\circledR}$ simulated samples.

It can be seen from the macrographs that a typical fusion welded joint is observed when the stroke is 4 and $6 \mathrm{~mm}$.

When the stroke is increased to 8 and $10 \mathrm{~mm}$, the weld joint 

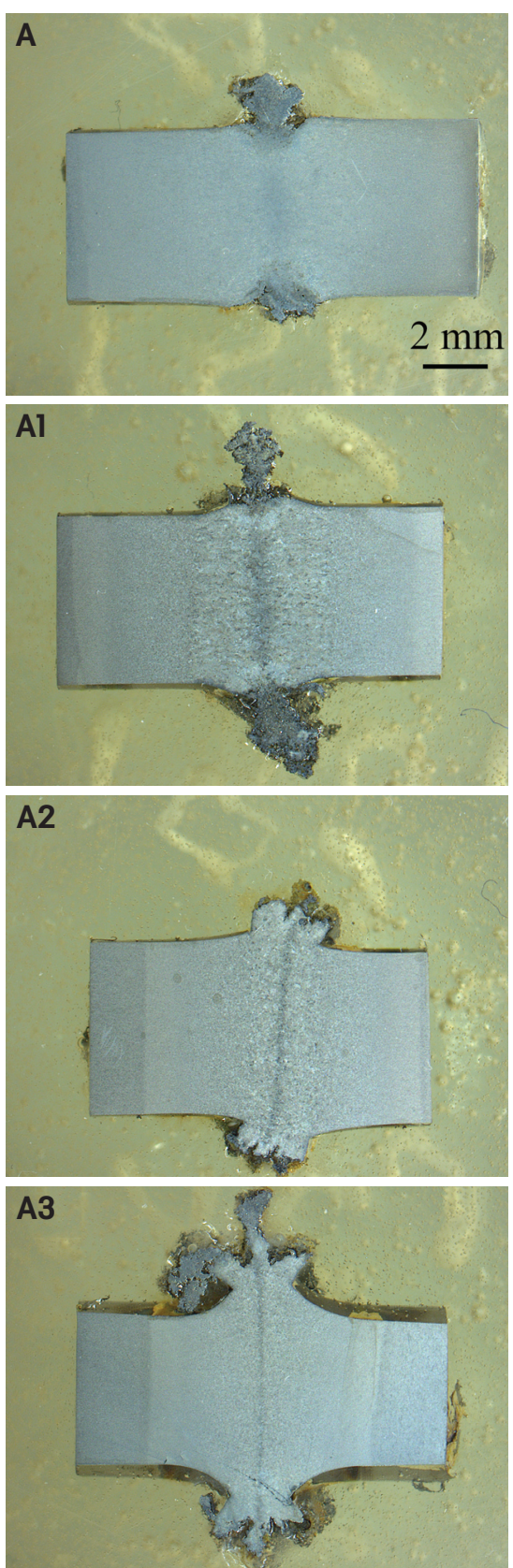
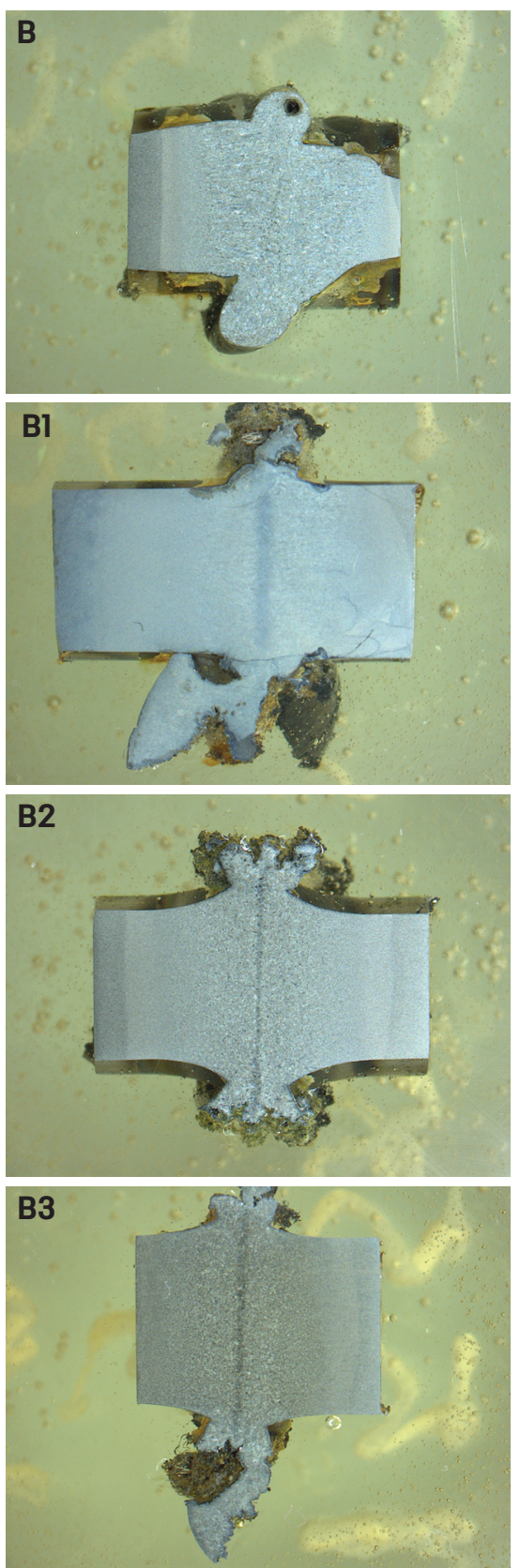
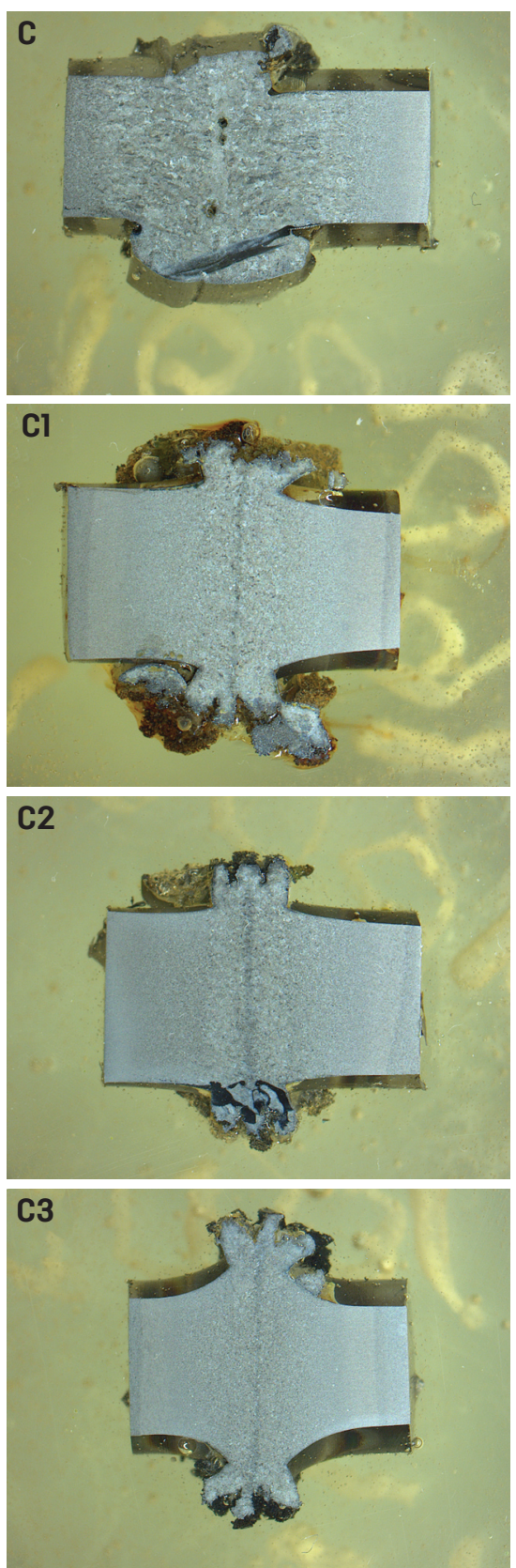

Fig. 7-Macrographs of the Gleeble ${ }^{\circledR}$ simulated samples. A-A3 show the macrographs of the $1500^{\circ} \mathrm{C}$ peak temperature samples with a stroke of $4 \mathrm{~mm}(\mathrm{~A}), 6 \mathrm{~mm}$ (A1), $8 \mathrm{~mm}$ (A2), and $10 \mathrm{~mm}$ (A3); B-B3 show the macrographs of the $1550^{\circ} \mathrm{C}$ peak temperature samples with a stroke of $4 \mathrm{~mm}(\mathrm{~B}), 6 \mathrm{~mm}(\mathrm{BI}), 8 \mathrm{~mm}(\mathrm{~B} 2)$, and $10 \mathrm{~mm}(\mathrm{~B} 3)$; $C$-C3 show the macrographs of the $1600^{\circ} \mathrm{C}$ peak temperature samples with a stroke of $4 \mathrm{~mm}$ (C); $6 \mathrm{~mm}$ (C1); $8 \mathrm{~mm}$ (C2); and $10 \mathrm{~mm}$ (C3).

is typical of a resistance weld with a solid state bondline. Since the solid-state weld joint along with flash (which is resolidified from liquid) is the characteristic of a resistance welded joint, it can be concluded the 8- and 10-mm stroke are more representative of a resistance welded joint. The validity of the physical simulation can only be accurate if the microstructure of the Gleeble ${ }^{\circledR}$ simulated seam weld matches with the industrially produced RW seam weld.

Figure 8 shows the microstructure comparison of the Gleeble ${ }^{\circledR}$ simulated seam weld with that of the industrially produced RW seam weld. It can be seen that when the peak temperature is $1500^{\circ} \mathrm{C}$ (Fig. $8 \mathrm{~A}-\mathrm{D}$ ), the microstructure of the weld joint and the HAZ of the Gleeble ${ }^{\circledR}$ simulated sample matches with the industrially produced RW pipe - Figs. $8 \mathrm{~A}-\mathrm{C}$ and 2 . The main difference between the Gleeble ${ }^{\circledR}$ simulated sample and the industrially manufactured RW pipe is that, in the industrially manufactured RW pipe, the TMAZ is clearly distinguishable (Fig. 2F), whereas in the Gleeble ${ }^{\circledR}$ simulated sample, characteristic grain flow in the TMAZ is not present (Fig. 8D). When the peak temperature is increased to $1550^{\circ} \mathrm{C}$ in Fig. $8 \mathrm{E}-\mathrm{H}$, it can be seen that the grain size of the seam weld and the HAZ of the Gleeble ${ }^{\circledR}$ simulated samples are larger than the industrially manufactured RW pipe - Figs. $8 \mathrm{E}-\mathrm{G}$ and 2 . Similar to the $1500^{\circ} \mathrm{C}$ peak temperature sample, 

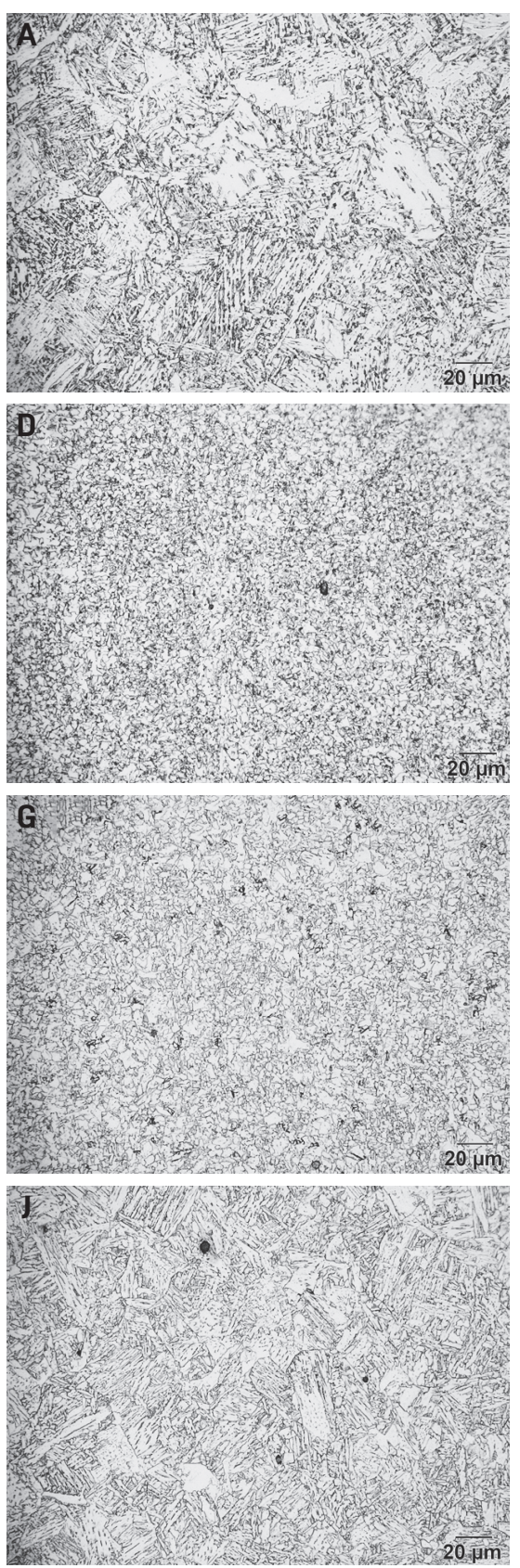
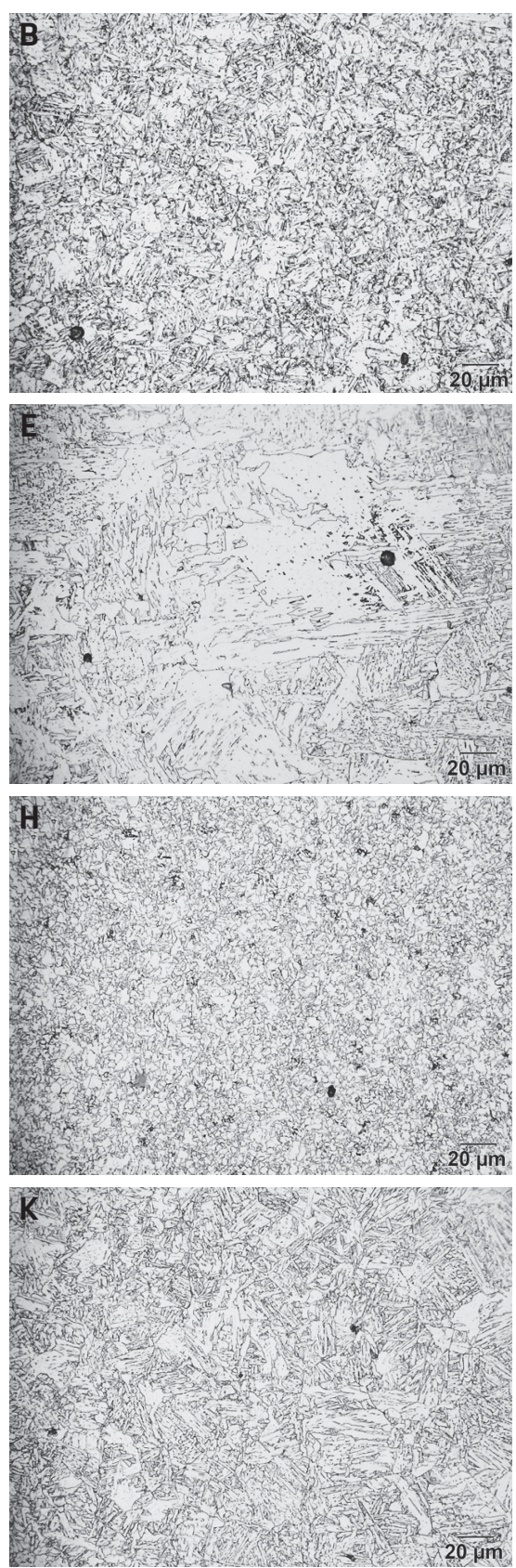
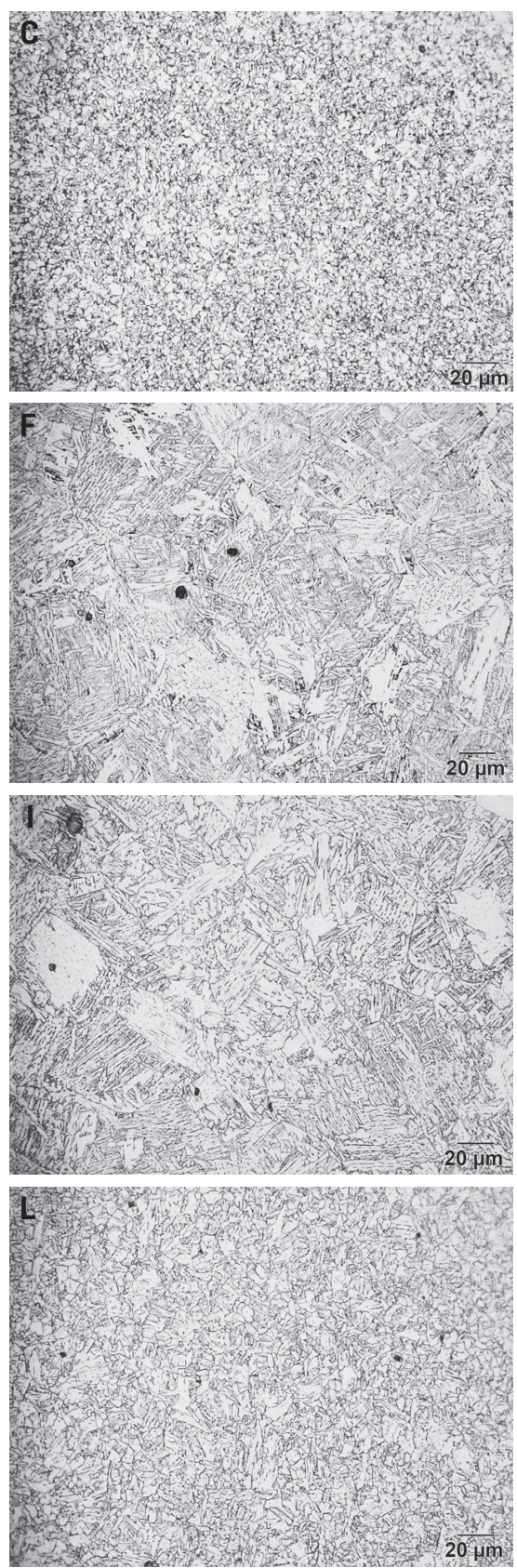

Fig. 8 - Microstructure of Gleeble ${ }^{\circledR}$ physical simulation samples. A-D - Peak temperature of $1500^{\circ} \mathrm{C}$ and $10-\mathrm{mm}$ stroke; E-H peak temperature of $1550^{\circ} \mathrm{C}$ and $10-\mathrm{mm}$ stroke; $1-\mathrm{L}$ - peak temperature of $1600^{\circ} \mathrm{C}$ and $10-\mathrm{mm}$ stroke.

characteristic grain flow in the TMAZ is not present - Fig. $8 \mathrm{H}$. When the peak temperature is increased to $1600^{\circ} \mathrm{C}$ in Fig. 8I-L, it can be seen that the grain size of the seam weld and the HAZ of the Gleeble ${ }^{\circledast}$ simulated samples are larger than the industrially manufactured RW pipe - Figs. 8I-K and 2. Similar to the $1500^{\circ} \mathrm{C}$ and the $1550^{\circ} \mathrm{C}$ peak temperature samples, characteristic grain flow in the TMAZ is not present Fig. 8L.

Considering the macrographs of the Gleeble ${ }^{\circledR}$ simulated samples in Fig. 7, and the microstructure comparison of the Gleeble ${ }^{\circledR}$ simulated samples with the industrially manufactured RW pipe (Fig. 8), it seems to suggest a peak temperature of $1500^{\circ} \mathrm{C}$ and a stroke of $10 \mathrm{~mm}$ provides a fair representation of the seam weld microstructure reproducible in a laboratory scale - Fig. 8A-D. Though a microstructure similar to the industrially RW welded pipe samples can be reproduced using Gleeble ${ }^{\circledR}$ physical simulation, the vertical stringers along the material flow direction observed in the industrial welded samples, as shown in Fig. 4, could not be reproduced. The likely reason for the lack of vertical stringers in the Gleeble ${ }^{\circledR}$ simulated samples could be due to the circumferential strain distribution in comparison to the plane strain condition during the industrial welding conditions. To verify the Gleeble ${ }^{\circledR}$ simulation experiments faithfully simulate the material flow, a physical simulation experiment was conducted on rectangular samples (refer to Fig. 1 ), which can reasonably simulate the plane strain welding conditions. 

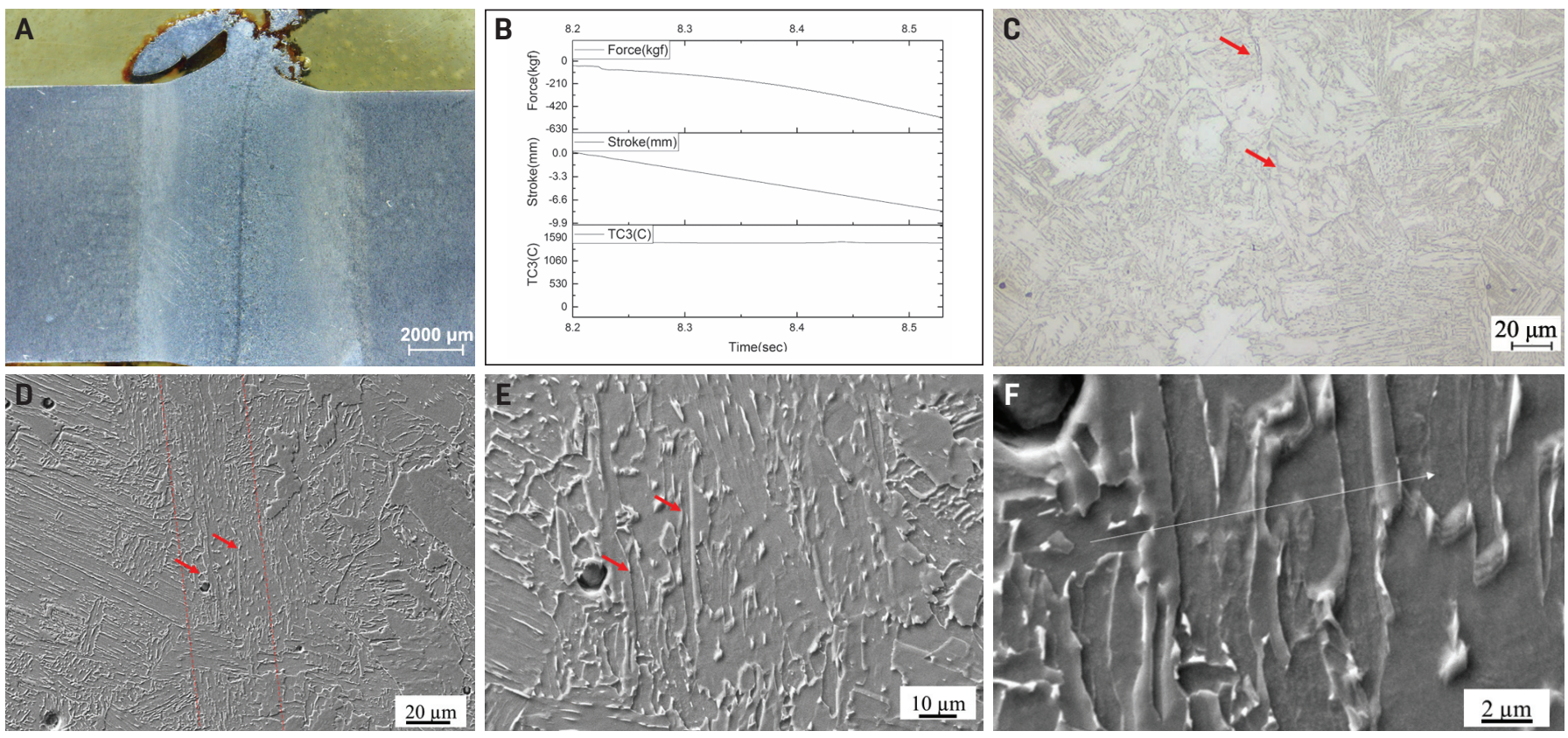
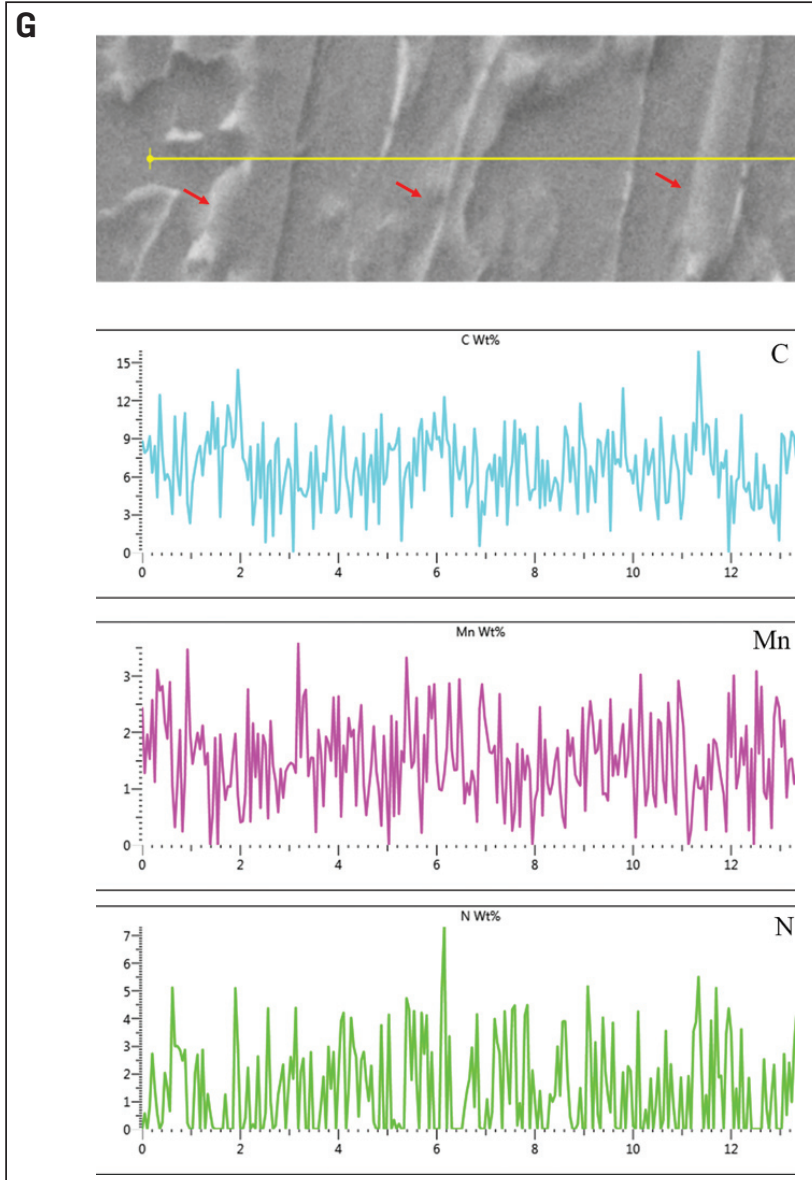

\section{Unidirectional Material Flow to Form Vertical Stringers}

Figure 9 shows the results of physical simulation on a rectangular sample (plane strain condition). It can be seen from the macrograph in Fig. 9A, similar to the round bar samples in Fig. 7, RW-type weld joint with flash is formed in the smaller direction of the rectangular-shaped sample; also
Fig. 9-Results of Gleeble ${ }^{\circledR}$ physical simulation of RW on rectangular samples (simulating plane strain condition). A Macrograph of the sample showing the presence of RW bondline with flash; B - Gleeble ${ }^{\circledR}$ recordings for the rectangular sample during the application of stroke; C - optical micrograph of the weld junction showing the presence of vertical features; $D$ - secondary electron image of the weld junction showing the vertical features at the weld junction; E, F- higher magnification secondary electron image of the weld junction showing vertical features; $\mathrm{G}$ - elemental line scan profiles across the vertical features corresponding the white line in $F$.

from the Gleeble ${ }^{\circledR}$ recordings during the stroke application (Fig. 9B), similar force response is recorded for the rectangular sample. The optical micrograph in Fig. $9 \mathrm{C}$ at the weld junction shows the presence of vertical features similar to the ones observed in the industrially welded pipe sample in Fig. 4. The secondary electron micrographs and the corresponding elemental line scan profiles in Fig. 9D-G show elemental segregation behavior with solute-enriched vertical features, similar to the as-welded pipe in Fig. 4, can be simulated using Gleeble ${ }^{\circledR}$ under plane strain conditions, providing further validity of our physical simulation experiments.

\section{Effect of Stroke on the RW Joint Formation with Flash in Gleeble ${ }^{\circledR}$}

Figures 10 and 11 show the representative recordings from Gleeble ${ }^{\circledR}$ during the physical simulation experiments at a peak temperature of $1500^{\circ} \mathrm{C}$ and for 4-mm stroke and 8-mm stroke, respectively. Figure $10 \mathrm{~A}$ shows the complete Gleeble ${ }^{\circledR}$ recording, indicating the force, stroke, and temperature evolution during the bond formation for a peak temperature of $1500^{\circ} \mathrm{C}$ and a stroke of $4 \mathrm{~mm}$. No solid-state RW bondline was produced, and the joint was fusion welding type. It can be seen there was a sudden compressive force before the heating cycle started. A small compressive force was intentionally applied prior to the start of the heating cycle to bring the two abutting surfaces of the base metal in contact before heating cycle started. Once the heating cycle started, the force response was ap- 

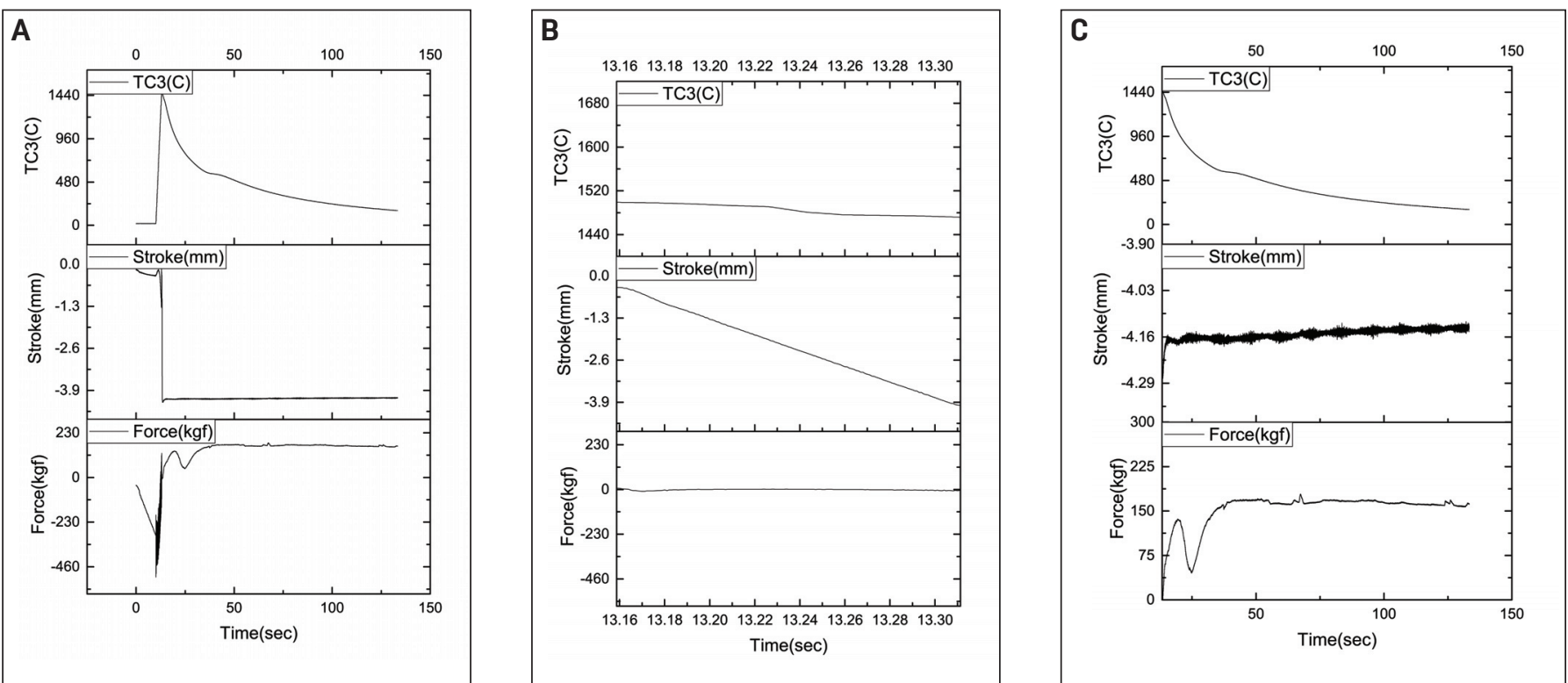

Fig. 10 - Representative Gleeble ${ }^{\circledR}$ recordings for a peak temperature of $1500^{\circ} \mathrm{C}$ and a stroke of $4 \mathrm{~mm}$. A Complete recording; $\mathrm{B}-$ recordings during the application of stroke; $\mathrm{C}$ - recordings during cooling and after the application of stroke.
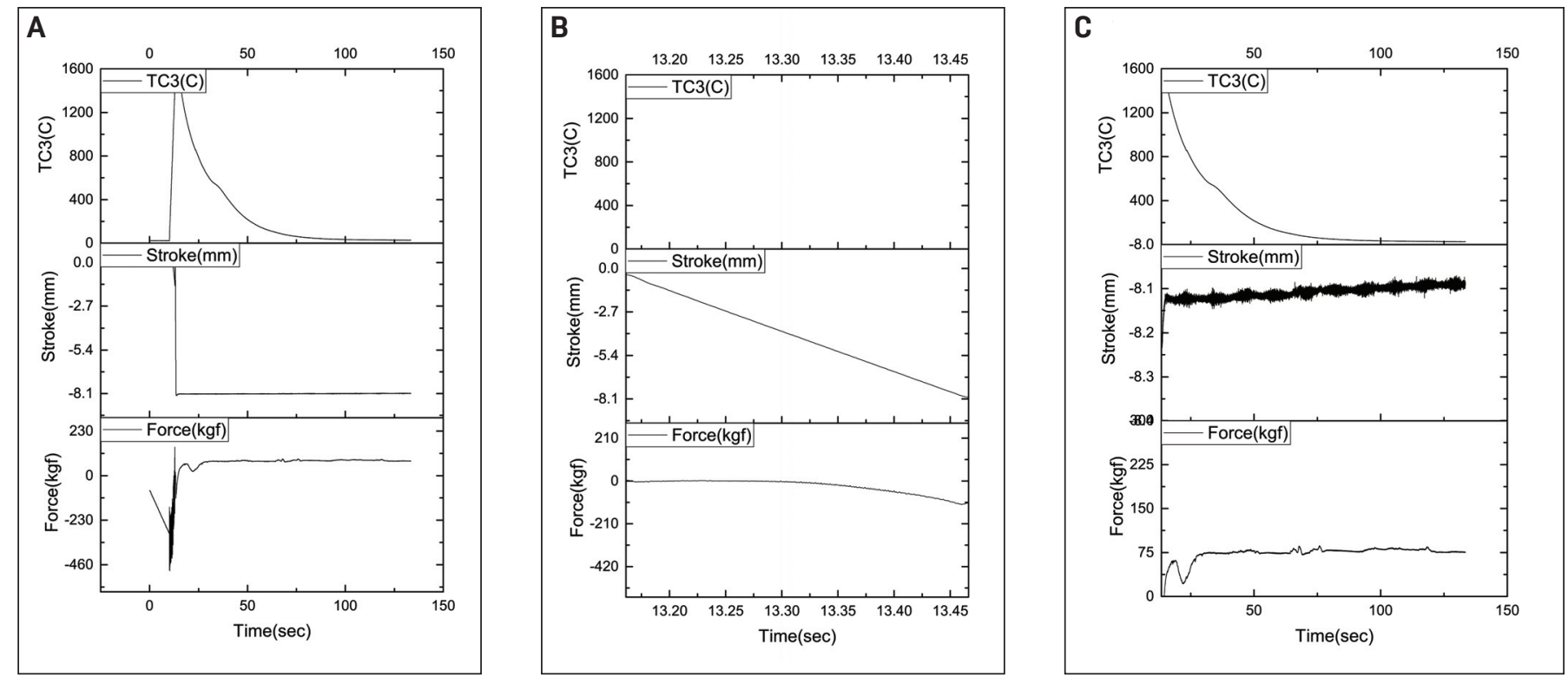

Fig. 11 - Representative Gleeble ${ }^{\circledR}$ recordings for a peak temperature of $1500^{\circ} \mathrm{C}$ and a stroke of $8 \mathrm{~mm}$. A-Complete recording; $\mathrm{B}-$ recordings during the application of stroke; and $\mathrm{C}$ - recordings during cooling and after the application of stroke.

proximately $0 \mathrm{kgf}$ during the heating cycle. Figure $10 \mathrm{~B}$ shows the Gleeble ${ }^{\circledR}$ recordings after the peak temperature was reached and during the application of stroke. It can be seen there was no significant variation in temperature during the stroke application period. The stroke produced compression and contact between the two samples. The force value was 0 kgf during the entire duration of stroke application. Figure $10 \mathrm{C}$ shows the Gleeble ${ }^{\circledR}$ recordings after the stroke application and during cooling. The force values recorded are the materials' mechanical response during cooling, whereas a constant stroke was maintained.

Figure 11A shows the complete Gleeble ${ }^{\circledR}$ recording, indicating the force, stroke, and temperature evolution during the
Gleeble ${ }^{\circledR}$ program for a peak temperature of $1500^{\circ} \mathrm{C}$ and a stroke of $8 \mathrm{~mm}$. It can be seen there was a sudden reduction in force before the heating cycle started. A compressive force was intentionally applied prior to the start of the heating cycle to bring the two surfaces of the base metal in contact before the heating cycle started. Once the heating cycle started, a tensile stress was generated in the sample, which increased the force response to approximately $0 \mathrm{kgf}$ during the heating cycle. Figure $11 \mathrm{~B}$ shows the Gleeble ${ }^{\circledR}$ recordings after the peak temperature was reached and during the application of stroke. It can be seen there was no large variation in temperature during the stroke application time. The stroke reduced, indicating compression and contact between the two samples. The force value 
was $0 \mathrm{kgf}$ during the initial stages of stroke application and then a compressive force was recorded. Figure $11 \mathrm{C}$ shows the Gleeble ${ }^{\circledR}$ recordings after the stroke application and during cooling. The force values recorded were the materials' mechanical response during cooling, whereas no change in stroke was observed because the stroke was controlled to a constant value.

The measurement of a compressive force during the RW squeeze is a clear indication of the solid-state bond formation. For the 4-mm squeeze case, no such compressive force was measured, and the bond formation was fusion welding.

\section{Discussion}

\section{Critical Conditions for Solid-State Bond Formation with a Flash}

The results in Figs. 6 to 11 showed if the squeeze is not sufficient to remove all the liquid formed during the RW, a solid-state bondline cannot be produced; rather, a fusion seam weld is produced. From the Gleeble ${ }^{\circledR}$ force recordings in Figs. 10 and 11, it can be seen if a fusion seam weld has formed, there is no resistance force recorded during the application of the squeeze. When the stroke is high enough to squeeze out all the liquid, resulting in a solid-state RW bondline, a compressive force was recorded during the stroke. Here, a model is proposed to understand the thermo-physical mechanism for such a force response during stroke application.

Both RW and the Gleeble ${ }^{\circledR}$ experiments were performed at a constant total stroke rate $(26 \mathrm{~mm} / \mathrm{s})$. The strain rate $(d \varepsilon / d t)$ during the application of stroke is a constant, which can be partitioned as the following:

$$
d \varepsilon_{\text {total }} / d t=d \varepsilon_{\text {elastic }} / d t+d \varepsilon_{\text {plastic }} / d t
$$

where $\varepsilon_{\text {elastic }}$ and $\varepsilon_{\text {plastic }}$ are the elastic component and plastic component of the total strain $\varepsilon_{\text {total }}$, respectively. After applying the constitutive material properties at high temperature, the above equation can be expressed in terms of the total stress (recorded response on the Gleeble ${ }^{\circledR}$ ) as

$$
\sigma_{\text {total }}=\sigma_{\text {plastic }}+\sigma_{\text {elastic }}
$$

The elastic component of the strain rate can be approximated as the strain rate due to the variation in thermal expansion coefficient as

$$
d \varepsilon_{\text {elastic }} / d t=\alpha_{\text {system }} d T / d t
$$

where $\alpha_{\text {system }}$ is the thermal expansion coefficient of the materials system in question. From the strain rate equation, the thermal stress/elastic component of stress can be expressed as

$$
\sigma_{\text {elastic }}=E(T) \alpha_{\text {system }} d T
$$

where $E(T)$ is the temperature-dependent elastic modulus of X70 steel. Because at the RW squeeze temperature the materials system is comprised of liquid $(L)$ and delta ferrite $(\delta)$, the above equation can be written as

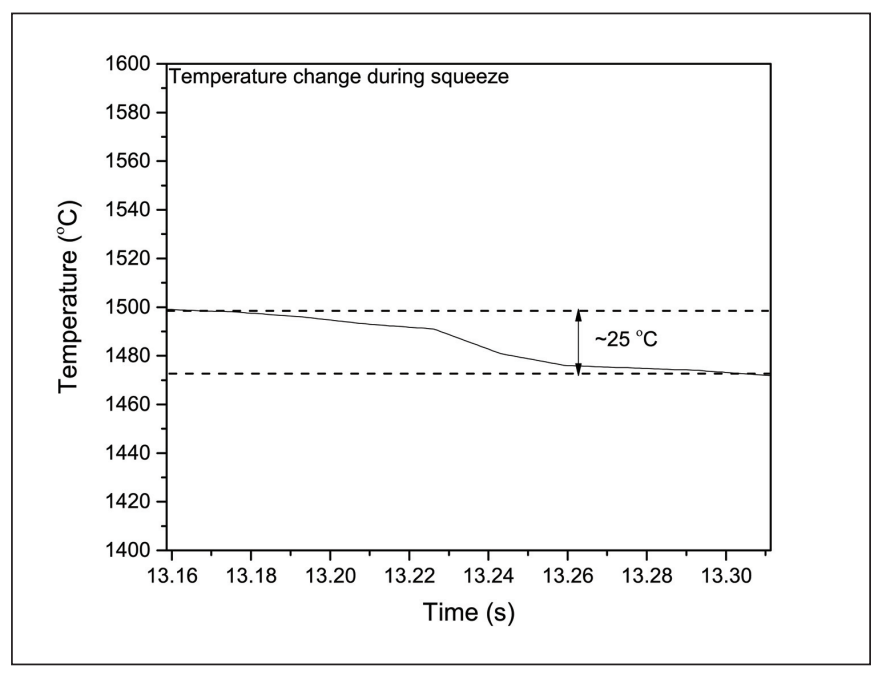

Fig. 12 - Variation in temperature during the application of weld squeeze.

$$
\begin{gathered}
\sigma_{\text {elastic }}=E(T) \Delta T\left(f_{L} \alpha_{L}+f_{\delta} \alpha_{\delta}\right) \\
\sigma_{\text {elastic }}=E(T) \Delta T\left(\alpha_{L}+f_{\delta}\left(\alpha_{\delta}-\alpha_{L}\right)\right) \\
\sigma_{\text {elastic }}=E_{L}(T) \Delta T \alpha_{L}+E_{\delta}(T) \Delta T\left(f_{\delta}\left(\alpha_{\delta}-\alpha_{L}\right)\right)
\end{gathered}
$$

where $\Delta T$ is the temperature change over the stroke, $f_{L}$ is the liquid fraction, $\alpha_{L}$ is the thermal expansion coefficient (CTE) of the liquid, $f_{\delta}$ is the solid fraction, and $\alpha_{\delta}$ is the CTE of the solid. Since the elasticity of the liquid $\left(E_{L}(T)\right)$ is negligibly small compared with that of the solid, the elastic stress is then

$$
\sigma_{\text {elastic }}=E_{\delta}(T) \Delta T\left(\alpha_{\delta}-\alpha_{L}\right) f_{\delta}
$$

For calculations using the above equation, the thermal expansion coeffcients of individual phases computed from ThermoCalc for the alloy studied were used.

The plastic component of the strain rate can be approximated by the flow stress of the material as (Ref. 28)

$$
\frac{d \varepsilon_{\text {plastic }}}{d t}=\frac{A D_{o} E b}{k T}\left[\frac{b}{d}\right]^{p}\left[\frac{\sigma}{E}\right]^{\frac{1}{n}} \exp \left(\frac{-Q}{R T}\right)
$$

where $E$ is the Young's modulus, $b$ is the Burgers vector, $d$ is the grain size, $n$ is the stress exponent (inverse of strain rate sensitivity $1 / m), p$ is the grain size exponent, $A$ is a microstructural-dependent constant, and $D_{o} \exp (-Q / R T)$ is the self diffusivity of iron. Grouping all the material constants as $C$, and expressing $T$ in terms of the temperature change during stroke application, the above equation can be written as

$$
\frac{d \varepsilon_{\text {plastic }}}{d t}=\varepsilon_{\text {plastic }}=C \sigma_{\text {plastic }}^{m} \exp \left(\frac{-Q}{R T}\right) \frac{1}{d t}
$$



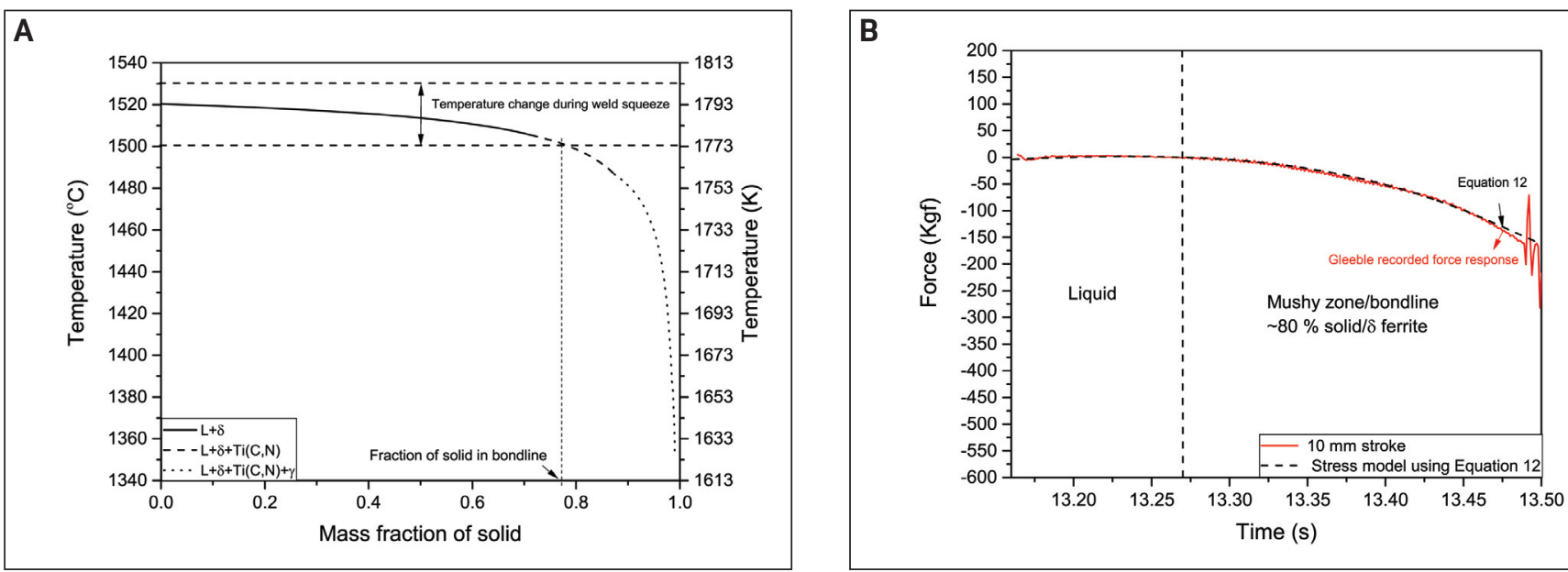

Fig. $13-A-$ Scheil solidification simulation for the alloy considered in the present study; B - demarcation of the force response recorded during Gleeble ${ }^{\circledR}$ into regions of expelling out liquid, and the formation of solid. The red solid line represents the recorded force response for a 10-mm stroke, and the black dotted line represents the force response fitted using Equation 12.

From the above equation, the plastic stress component by solid $\delta$ ferrite can be expressed as

$$
\sigma_{\text {plastic }}=f_{\delta}\left[\left(\frac{\dot{\varepsilon}}{C}\right) \exp \left(\frac{Q}{R T}\right)\right]^{\frac{1}{m}}
$$

Substituting Equations 8 and 11 in Equation 2, the recorded stress/force response by Gleeble ${ }^{\circledR}$ can be written as follows:

$$
\sigma_{\text {total }}=\left[\left(\left(\frac{\dot{\varepsilon}}{C}\right) \exp \left(\frac{Q}{R T}\right)\right)^{\frac{1}{m}}+E_{\delta}(T) \Delta T\left(\alpha_{\delta}-\alpha_{L}\right)\right] f_{\delta}
$$

Since the average strain rate $(\dot{\varepsilon})$ experienced during the squeeze application is a constant, and the temperature reduction during the application of squeeze is small (refer to Fig. 12), the deformation during the squeeze can be approximated by an isothermal process.

Therefore, the quantities in the brackets of Equation 12 can be approximated as a constant with a negative sign. The total force is then mainly dependent on the fraction of delta ferrite, $f_{\delta}$. The shape/slope of the force response during stroke application will be predominantly governed by the fraction of delta ferrite present.

The fraction of solid formed can be calculated by the Scheil equation. Figure 13A represents the Scheil solidification simulation for the material considered in this study. Using the change in fraction of solid with temperature from the Scheil solidification simulation, the fraction of solid can be represented as a function of time (incorporating the temperature change during welding), which can in turn be used in Equation 12 to determine the material constant, i.e., the quantities in the brackets, as the fitting parameter - Fig. 13B. Comparing the fraction of solid in the system and the temperature change during stroke application (refer to Fig.
12B), the force response recorded from Gleeble ${ }^{\circledR}$ can be divided into regions of expelling out the liquid during stroke application, and the formation of solid as shown in Fig. 13B.

Based on the above argument, we propose if the force response during stroke application does not change significantly, the stroke is not sufficient enough to expel the liquid out of the system, resulting in a fusion welded joint (refer to Fig. 7 for a 4-mm stroke). Whereas, if the force response during stroke application is compressive, the stroke is sufficient enough to expel the liquid out of the system, resulting in a resistance seam weld (solid-state bondline and the flash) (refer to Fig. 7 for 8-mm/10-mm strokes).

Thus, the force response during stroke application can be used as a predictive tool to determine the nature of the weld joint formed.

\section{Mechanism of Joint Formation during RW}

The force analysis in Fig. 13 shows during the squeeze to form the bondline, the bond region in the bondline is comprised of a mushy zone structure (with approximately $80 \%$ solid and 20\% liquid) and is not entirely in a solid state. Due to segregation, the liquid present in the bond region must be enriched in solute elements. Specifically, the delta ferrite in the dendritic core regions is much leaner in alloy elements than the interdendritic liquid regions, as shown in Fig. 14.

Comparing the theoretical analyses presented in Figs. 13 and 14 to the experimental results presented in Fig. 4, the following mechanism is proposed for the seam weld formation during RW. When the two abutting edges reach the maximum temperature just before the " $V$ convergence" where the two edges of the skelp come into contact, the thermal gradient $(G)$ is the least near the edges of the base metal, and it progressively increases towards the colder end of the base metal. Thus, on cooling without the application of weld squeeze, the hot end of the base metal skelp must solidify in a manner similar to the weld center line, resulting in the columnar/equiaxed dendritic structure (Ref. 29). Away from the hot end of the base metal skelp, closer to the colder end of the base metal (high G), on cooling without the application of weld squeeze, 

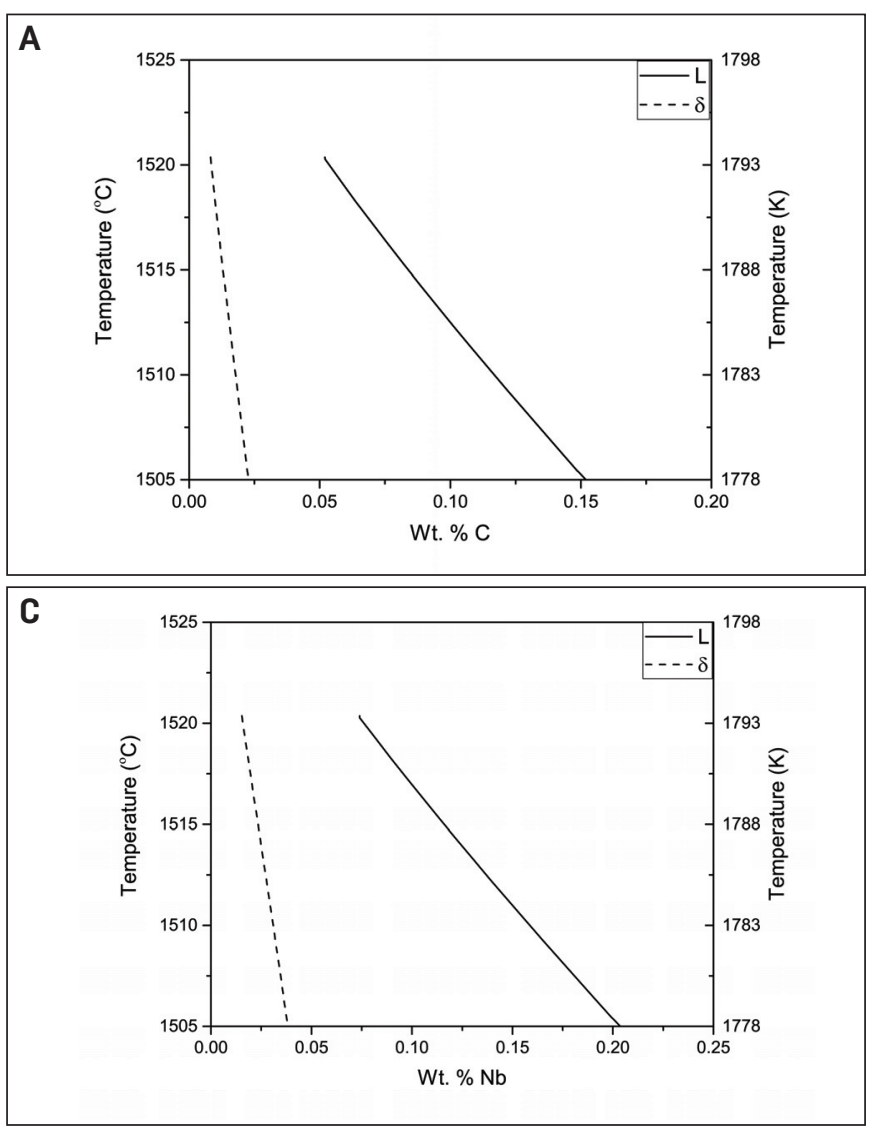

Fig. 14 - Predicted solute partitioning behavior between liquid and delta ferrite during solidification using ThermoCalc. $A-C ; B-M n ; C-N b ; D-T i ; E-N$.

the materials must solidify in a manner similar to the weld interface, resulting in a cellular structure (Ref. 29) — refer to Fig. 15A.

Once the weld squeeze is applied, owing to the hourglass nature of the temperature distribution, the displacement fields in the material will be as shown in Fig. 15, image $C 1$. The weld squeeze results in the flow of the dendritic grains in a direction perpendicular to the direction of application of weld squeeze. From the theoretical analyses presented in Fig. 13, it is clear the liquid is expelled out, resulting in a mushy zone ( $20 \%$ liquid enriched in solutes $+80 \%$ delta ferrite depleted in solutes) at the weld joint. Therefore, the delta ferrite grains will be deformed along the displacement field during the application of weld squeeze as shown in Fig. 15, images C2 and C3.

The delta ferrite grains undergo solid-state phase transformation into austenite, which in turn transforms into alpha ferrite (refer Fig. 2), whereas the liquid film that is enriched in solute transforms into austenite, which is enriched in solutes, and transforms into M/A modules, which are elongated along the direction of displacement field. This explains the presence of stringers-shaped $\mathrm{M} / \mathrm{A}$ modules across the entire length of the weld joint. Similarly, the presence of stringers of M/A modules in the weld joint was also observed in the work conducted by Yan (Ref. 22) in high-frequency induction welded joints of X65 pipeline steels. Since all of the delta ferrite grains present during welding will undergo solid-state phase transformation into austenite, which in turn will transform into al-
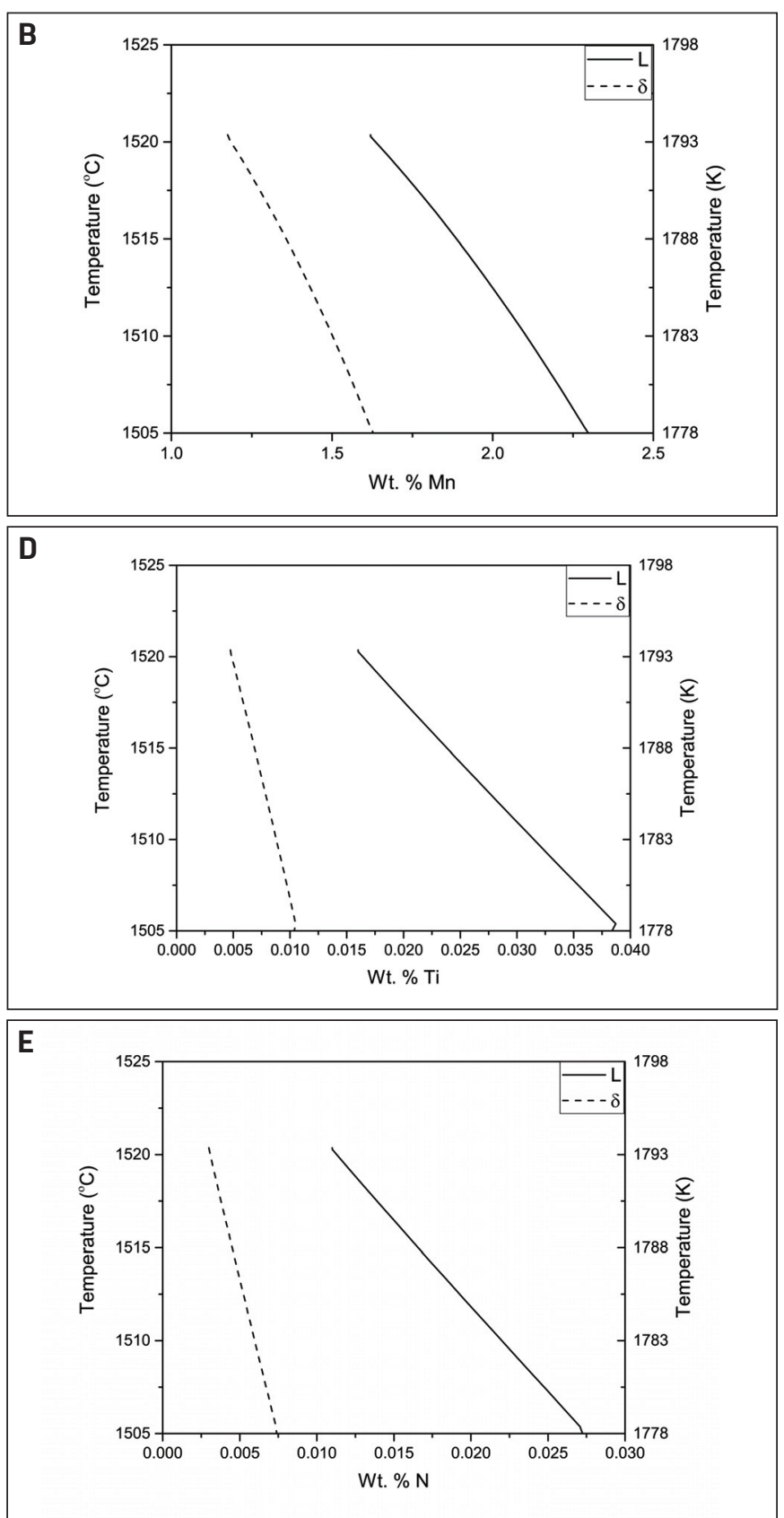

pha ferrite, the presence of high-temperature delta ferrite was verified indirectly by capturing the chemical signature at room temperature, as shown in the experimental EDX line scan results for Mn (Fig. 4E), where it can be seen that the concentration of Mn enrichment in M/A stringers (solidified from liquid) matches well with the Mn enrichment predicted from Scheil calculations in Fig. 14B. Also, because the weld joint was comprised predominantly of delta ferrite, which later transformed to austenite and further into alpha ferrite during cooling, which is depleted in carbon (refer to Fig. 14A), this results in the reduction in hardness of the bondline (Fig. 5) in comparison to the CGHAZ, despite having the same microstructure of predominantly bainitic ferrite (refer to Fig. 2); this provides a physical explanation for the "decarburization" phenomenon observed in the resistance weld joints. Atom probe tomography for accurate determination of chemical composition 


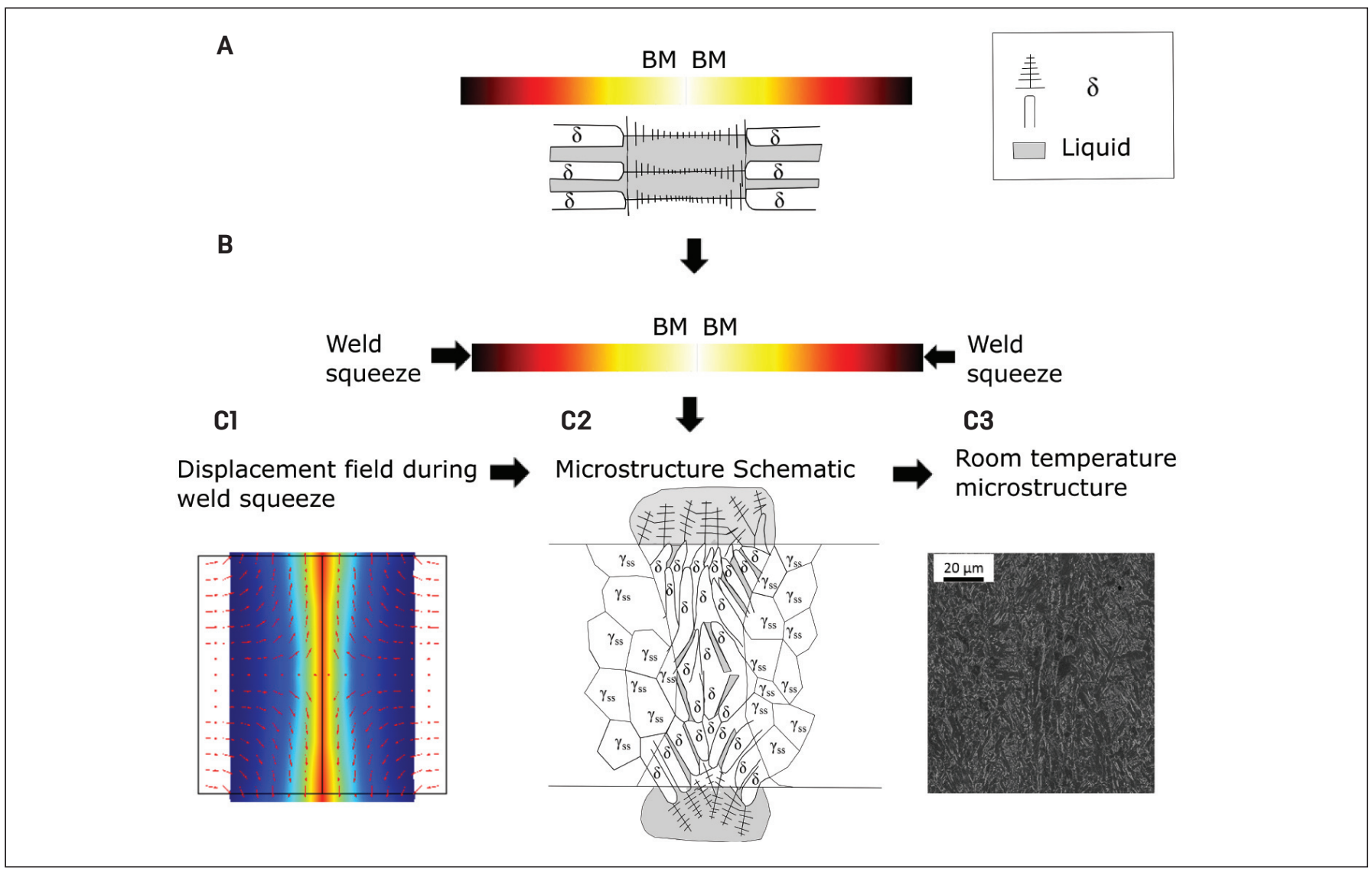

Fig. 15 - Schematic of joint formation mechanism during HF-RW. It should be noted the schematic of dendrite growth is not to scale and is purely used as a visual aid to understand the microstructure evolution occurring in the bondline, which itself is narrow.

of the resistance weld joint have also been conducted to further verify our proposal that the RW bondline is comprised of mushy zone. However, for brevity of this paper, the APT results will be published separately (Ref. 30). Although the theoretical analyses and the experimental results indicate a mushyzone-type deformation during RW bond formation, characterizing the joint formation insitu using neutron diffraction will provide further support of the proposed bond formation mechanism and provide newer insights.

\section{Conclusions}

In this study, a Gleeble ${ }^{\circledR}$ thermo-mechanical simulator was used to physically simulate the seam weld formation (RW bondline + flash) during RW for the first time, and using the recordings of force, temperature, and stroke during welding, a physical mechanism for joint formation during RW is proposed.

The following conclusions can be drawn:

1. A temperature close to the liquidus temperature, and a high enough stroke are both necessary for the formation of the solid-state resistance seam weld and a flash. A higher peak temperature in combination with high stroke will result in the formation of a resistance seam weld, but severe grain growth is observed in the microstructure of the seam weld. If the stroke is not sufficient to remove all the liquid formed, a resistance seam weld is not produced; rather, a fusion welded seam weld is produced.
2. Although the hourglass shape of the resistance seam weld cannot be simulated due to the low frequency resistive volume heating in Gleeble ${ }^{\circledR}$, a solid-state seam weld with flash, and a comparable microstructure within $\pm 0.5 \mathrm{~mm}$ from the bondline, is successfully simulated.

3. The force response during stroke application can be used as a predictive tool to determine the nature of the weld joint formed during the Gleeble ${ }^{\circledR}$ experiment. From the force response, in combination with Scheil solidification simulation, it was found the weld joint in RW is formed from a mushy zone comprised of delta ferrite and liquid at high temperature. On cooling post welding, the high-temperature delta ferrite regions eventually transformed into ferritic microstructure, whereas the solute enriched liquid film transformed into $\mathrm{M} / \mathrm{A}$ stringers.

4. The presence of a mushy zone at the weld joint during the bond formation comprising of delta ferrite and liquid provides a physical explanation for the decarburization feature commonly observed in RW joints.

\section{Acknowledgments}

The authors acknowledge the support by Natural Sciences and Engineering Research Council of Canada through a Collaborative Research and Development grant. The authors also acknowledge Lorne Good for help with the Gleeble ${ }^{\circledR}$ experiments. 
References

1. Mohammadijoo, M. 2017. Development of a welding process to improve welded microalloyed steel characteristics. PhD thesis. University of Alberta. DOI: 10.7939/R30G3H97F

2. Anderson, N. E. 2018. Influence of the post-weld heat treatment on the low-temperature toughness of ERW API X70 line pipe. Masters thesis. University of Alberta. DOI: 10.7939/R3DJ58Z4S

3. Anijdan, S. H. M., Khafri, M., Jafarian, H. R., and Khoshakhlagh, A. R. 2018. Role of cube texture on toughness variation of electric resistance welded steel. Science and Technology of Welding and Joining 23(5): 387-393. DOI: 10.1080/13621718. 2017.1401337

4. Choi, J., Chang, Y., Kim, C., Oh, J., and Kim, Y. 2004. Penetrator formation mechanisms during high-frequency electric resistance welding. Welding Journal 83(1): 27-s to 31-s.

5. Fukai, M., Karasawa, J., Shiotani, O., Ogawa, Y., Morita, M., and Sugie, Y. 1988. Manufacturing techniques and characteristics of high grade ERW line pipe API 5L X80. Kawasaki Steel Technical Report (18): 25-31.

6. Goto, S., Nakata, H., Toyoda, S., Okabe, T., and Inoue, T. 2017. Control of microstructures and the practical properties of API X80 grade heavy-wall high- frequency electric resistance-welded pipe with excellent low-temperature toughness. Metallurgical and Materials Transactions A 48(10): 5075-5084. DOI: 10.1007/ s11661-017-4242-3

7. Haga, H., Aoki, K., and Sato, T. 1980. Welding phenomena and welding mechanisms in high frequency electric resistance welding $-1^{\text {st }}$ report. Welding Journal 59(7): 208-s to 212-s.

8. Hong, H. U., Kim, C. M., and Lee, J. B. 2005. Fatigue behavior of electric resistance welded seams in API-X70 Steel. Proceedings of the Fifteenth International Offshore and Polar Engineering Conference 8: 185-190.

9. Hong, H. U., Lee, J. B., and Choi, H. J. 2009. Improvement of resistance to hydrogen induced cracking in electric resistance welded pipes fabricated with slit coils. Metals and Materials International 15(1): 133-139. DOI: 10.1007/s12540-009-0133-5

10. Karani, A., Koley, S., and Shome, M. 2019. Failure of electric resistance welded API pipes - Effect of centre line segregation. Engineering Failure Analysis 96(5): 289-297. DOI: 10.1016/ j.engfailanal.2018.10.018

11. Kim, C. M., and Kim, J. K. 2009. The effect of electromagnetic forces on the penetrator formation during high-frequency electric resistance welding. Journal of Materials Processing Technology 209: 838-846. DOI: https:10.1016/j.jmatprotec.2008.02.079

12. Kim, D., Kim, T., Park, Y., Sung, K., Kang, M., Kim, C., et al. 2007. Estimation of weld quality in high-frequency electric resistance welding with image processing. Welding Journal 86(3): 71-s to 80-s

13. Kimchi, M. 2011. High-frequency welding. ASM Handbook Volume 6A: 456-462.

14. Komine, I., Takahashi, I., and Ishiro, S. 1987. Heat control for electric resistance welding in steel pipe production. IEEE Control Systems Magazine 10: 10-14. DOI: 10.1109/MCS.1987.1105359

15. Kyada, T., Shant, J. R., Goyal, D., Goyal, R., and Kathayat, T. 2015. Analysis of micro cracks near weld line in ERW pipe of API 5L X70M grade. Journal of Failure Analysis and Prevention 15: 344350. DOI: $10.1007 / \mathrm{s} 11668-015-9950-7$

16. Shin, S. Y., Oh, K., Kang, K. B., and Lee, S. 2009. Effects of complex oxides on charpy impact properties of heat affected zones of two API X70 linepipe steels. ISIJ International 49(8): 1191-1199. DOI: 10.2355/internationalist.49.1191
17. Su, X., Laver, A., Gianetto, J., Liang, J., Tyson, W. R., and Matsuno, S. 2017. Charpy toughness of ERW seam welds. Journal of Pipeline Engineering 16(3): 149-167.

18. Takatoshi, O., Koichi, Y., and Kazuhiro, N. 2014. Dynamic observations of welding phenomena and finite element analysis in high frequency electric resistance welding. Journal of the Japan Welding Society 32(3): 156-163. DOI: 10.1080/09507116.2016. 1142203

19. Takatoshi, O., Yukinori, I., and Satoshi, I. G. I. 2015. High reliability technology of the weld zone of high-frequency electric resistance welding linepipes. JFE Technical Report 20: 125-132.

20. Tomohiro, I., Masahito, S., Takatoshi, O., and Yutaka, M. 2013. Development of advanced electric resistance welding (ERW) linepipe "Mighty Seam ${ }^{\mathrm{TM}}$ " with high quality seam weld suitable for extra-low temperature services. JFE Tech. Rep. 18: 18-22.

21. Williams, J. G. 2007. Advances in steels for high strength ERW linepipe application in Australia. Materials Forum 31: 1-10.

22. Yan, P. 2011. High frequency induction welding \& postwelding heat treatment of steel pipes. PhD thesis. University of Cambridge.

23. Col, M., and Yilmaz, M. 2006. The determination of heat treatment parameters of x52 microalloyed steel after high frequency welding. Materials and Design 27: 507-512. DOI: 10.1016/ j.matdes.2004.11.025

24. Changchun, Y. 1996. Metallographic examination evaluation criteria and control for ERW pipe production. Tube International: 153-155.

25. Robert, K. N. High frequency welding - The process and applications. Thermatool Corp. technical publication.

26. Gungor, O. E., Yan, P., Thibaux, P., Liebeherr, M., Bhadeshia, H. K. D. H., and Quidort, D. 2010. Investigations into the microstructure-toughness relation in high frequency induction welded pipes. $8^{\text {th }}$ International Pipeline Conference: 577-585. DOI: 10.1115/IPC2010-31372

27. Tamura, I. 1987. Some fundamental steps in thermomechanical processing of steels. ISIJ International 27: 763-779.

28. Bakshi, P. K., and Kashyap, B. P. 1995. Stress-strain rate relations for high-temperature deformation of two-phase $\mathrm{Al}-\mathrm{Cu}$ alloys. Journal of Materials Science 30(20): 5065-5072. DOI: 10.1007/BF00356050

29. Kou, S. 2003. Welding Metallurgy. $2^{\text {nd }}$ Ed. John Wiley \& Sons Inc.

30. Sharma, N., Kannan, R., Li, L., Unocic, R., and Poplawsky, J. Mechanism for carbon depletion at bondline of high frequency electric resistance welded and post-weld heat-treated X70 pipeline steel. Unpublished research.

RANGASAYEE KANNAN (rangasay@ualberta.ca), LEIJUN LI (lei jun@ualberta.ca), and LULU (LUCAS) GUO (Iguo@ualberta.ca) are with the Department of Chemical and Materials Engineering, University of Alberta, Edmonton, Alberta, Canada. NEIL ANDERSON (Neil.Anderson@evrazna.com), MUHAMMAD RASHID (Muhammad.Rashid@evrazna.com), LAURIE COLLINS (Laurie.Collins@evrazna.com), and MUHAMMAD ARAFIN (Muhammad.Arafin@evrazna.com) are with EVRAZ Inc. NA, Regina, SK, Canada. 